Published in final edited form as:

Hear Res. 2014 May ; 0: 72-88. doi:10.1016/j.heares.2014.03.008.

\title{
Photons and Neurons
}

Claus-Peter Richter ${ }^{1,2,3,{ }^{*}}$ and Xiaodong Tan ${ }^{1}$

${ }^{1}$ Northwestern University Feinberg School of Medicine, Department of Otolaryngology, $303 \mathrm{E}$. Chicago Ave, Searle 12-561, Chicago, IL 60611, USA

${ }^{2}$ Dept. of Biomedical Engineering, Northwestern University, 2145 Sheridan Road, Tech E310, Evanston, IL 60208, USA

${ }^{3}$ The Hugh Knowles Center, Department of Communication Sciences and Disorders, Northwestern University, Evanston, IL, 60208, USA

\section{Abstract}

Methods to control neural activity by light have been introduced to the field of neuroscience.

During the last decade, several techniques have been established, including optogenetics, thermogenetics, and infrared neural stimulation. The techniques allow investigators to turn-on or turn-off neural activity. This review is an attempt to show the importance of the techniques for the auditory field and provide insight in the similarities, overlap, and differences of the techniques. Discussing the mechanism of each of the techniques will shed light on the abilities and challenges for each of the techniques. The field has been grown tremendously and a review cannot be complete. However, efforts are made to summarize the important points and to refer the reader to excellent papers and reviews to specific topics.

\section{Introduction}

Neural stimulation with photons is not a novel idea. Efforts to stimulate frog muscle tissue and nerve fibers with visible light were reported as early as 1891 (Arsonval, 1891). While the initial results were not convincing, recent developments showed that neural stimulation with light is possible and shaped the field of neurostimulation and neuromodulation. Figure 1 shows typical radiation wavelengths that are used today for neural stimulation. Four different approaches can be distinguished, (1) direct stimulation of the target structure with infrared radiation (infrared neural stimulation or INS), (2) activation of ion channels expressed in neurons with visible light (optogenetics), (3) activation of temperature sensitive ion channels expressed in neurons with heat (thermogenetics), (4) and in the cochlea activation of neurons through mechanical events created by laser radiation. Hereby, the

(C) 2014 Elsevier B.V. All rights reserved.

Claus-Peter Richter, M.D., Ph.D.; Northwestern University Feinberg School of Medicine; Department of Otolaryngology; Searle Building 12-470; 303 E. Chicago Avenue; Chicago, IL 60611-3008; U.S.A.; Phone: (312) 503 1603; FAX: (312) 503 1616; cri529@ northwestern.edu.

Publisher's Disclaimer: This is a PDF file of an unedited manuscript that has been accepted for publication. As a service to our customers we are providing this early version of the manuscript. The manuscript will undergo copyediting, typesetting, and review of the resulting proof before it is published in its final citable form. Please note that during the production process errors may be discovered which could affect the content, and all legal disclaimers that apply to the journal pertain. 
interactions between the photons and the tissue determine the mechanism by which stimulation occurs. Wavelength of the radiation, radiant energy, and temporal properties of energy delivery characterize the light source, while photon absorption, reflection, and scattering characterize the tissue properties (Jacques, 2013). Depending on the light source and the irradiated tissue one can distinguish among photothermal, photoacoustical, and photochemical effects. Photochemical effects come from endogenous or exogenous chromophores, which absorb the radiation and convert it into chemical energy. Heating of the target tissue after the absorption of the photon in the target tissue can lead to pressure waves and to photoacoustic effects. In addition to the information provided throughout the paper on the photon-tissue interaction, detailed descriptions and reviews on photon-tissue interactions have been published (for reviews see Jacques, 1992; Tuchin, 2000; Niemz, 2004; Welch and van Gemert, 2012; Jacques, 2013).

\section{Early efforts to stimulate neurons with light}

An overview of the efforts is given in Table 1. Subsequent to D'Arsonval's experiments, Arvanitaki and Chalazonitis (1961) demonstrated that inhibition and excitation can be triggered in unstained but pigmented nerve cells by irradiation with radiation of different wavelengths, ranging from the visible $(\lambda=400-700 \mathrm{~nm})$ and infrared $(\lambda=750-4000 \mathrm{~nm})$. They used several preparations for optical neural stimulation, such as Aplysia and Sepia giant axon. In response to the irradiation, most neurons were depolarized. However, some nerve cells in an Aplysia preparation decreased their neural activity during infrared irradiation. The hypothesized mechanism for both, excitation and inhibition, was the absorption of light by an undetermined cellular molecule.

To map intracellular connections of the abdominal ganglion of Aplysia californica, Fork (1971) irradiated its ganglion with continuous blue $(\lambda=488 \mathrm{~nm})$, green $(\lambda=515 \mathrm{~nm})$, or near infrared radiation $(\lambda=1060 \mathrm{~nm})$ and evoked excitatory and inhibitory neural responses selectively and reversibly for $2-5 \mathrm{~s}$. Stimulation of the neurons was possible without damaging the cells. He also examined possible mechanisms for the light-evoked stimulation of the cells by changing the ion content of the bathing solution and by applying different ion channel blockers. He concluded that the irradiation opens sodium-ion channels and may activate the sodium-potassium ion exchange pump. However, the persistence of residual responses in the presence of ouabain suggests a more complex mechanism.

For optical stimulation concurrent with electrical stimulation a variety of continuous and pulsed optical sources have been used to modulate electrically evoked neural activity. The effect of irradiation at wavelengths in the ultraviolet $(\lambda<370 \mathrm{~nm}$; continuous wave (cw) irradiation for $>2$ minutes) on the excitability of myelinated nerve fibers has been studied (Booth et al., 1950). Irradiation of the node of Ranvier increased the electrical stimulation threshold and decreased the electrically evoked action potential amplitude. Neural responses occurred only for radiation wavelengths below $\lambda=320 \mathrm{~nm}$ with a maximum effect at about $\lambda=265 \mathrm{~nm}$. The authors argue that the radiation destroys thiamin, which has an absorption maximum at $\lambda \sim 260 \mathrm{~nm}$. The loss of thiamin could explain the findings. An alternate explanation is the neural damage from the radiation. In contrast to nodal stimulation, irradiation of the nerve's internodal region lowered the stimulation threshold. Post stimulus 
histology showed a loss in birefringent activity after internodal stimulation indicating nerve damage.

Olson $(1981 b$; 1981a) irradiated unstained neuronal cultures of rat cerebellar tissue with a ruby laser ( $\lambda=694.3 \mathrm{~nm}, \tau_{\mathrm{p}}=100 \mu \mathrm{s}, Q=0-390 \mu \mathrm{J} / \mathrm{pulse}$, laser spot radius $\sim 0.2 \mathrm{~mm}$ ) or a dye laser ( $\lambda$ discrete bands between 490 and $685 \mathrm{~nm}, \tau_{\mathrm{p}}=1 \mu \mathrm{s}, Q=15$ to $360 \mu \mathrm{J} / \mathrm{pulse}$, laser spot radius $\sim 3.5 \mu \mathrm{m}$ ) concurrent with electric current pulses. At low radiant energies, irradiation had no effect on the electrically evoked responses. However, at higher energies ( $Q>390 \mu \mathrm{J} / \mathrm{pulse}$ ), the laser irradiation reduced the electrical excitability of the neurons. At energies where laser irradiation modified electrically evoked neural activity, mitochondrial damage was seen in images taken with a transmission electron microscope (TEM). The authors excluded the possibility of a photochemical reaction and concluded that the irradiation induced a local heating in the mitochondria, which led to decreased neural activity and to tissue damage (Olson et al., 1981b; Olson et al., 1981a). They estimated that the radiant energy delivered to the tissue increases the average temperature of the cell by only $0.1{ }^{\circ} \mathrm{C}$, but that local heating of the mitochondria will result in an approximately $26{ }^{\circ} \mathrm{C}$ increase in temperature, leading to damage of the mitochondria and a release of calcium into the cytoplasm.

Balaban et al. (1992) irradiated silent and spontaneously active neurons of snail ganglia with a HeNe laser $\left(\lambda=632.8 \mathrm{~nm}, E=0.05\right.$ to $\left.4 \mathrm{~W} / \mathrm{cm}^{2}, \mathrm{cw}\right)$. They could modify the rate of action potentials (APs) in spontaneously active neurons, but could not evoke APs in silent neurons. The authors concluded that the temperature effects of irradiation were responsible for the results.

Uzdensky and Savransky (1997) demonstrated an initial rate increase of electrically evoked action potentials followed by a decrease when irradiating neurons with a dye laser $(\lambda=434$ to $600 \mathrm{~nm}, \tau_{\mathrm{p}}=15 \mathrm{~ns}, f=400 \mathrm{~Hz}, E=0.25-5 \mathrm{~kW} / \mathrm{cm}^{2}$ ). They found a maximum change in the electrically evoked neural responses with $\lambda=460 \mathrm{~nm}$ radiation. Using the same power density, they did not observe any change in electrically evoked neural activity with $\lambda=580$, 600 , or $632 \mathrm{~nm}$ radiation. The authors hypothesized that irradiation effects were a result of light absorption by flavins and a subsequent calcium $\left(\mathrm{Ca}^{2+}\right)$ release from mitochondria.

Wesselmann and coworkers utilized a pulsed, Nd:YAG laser $\left(\lambda=1064 \mathrm{~nm}, \tau_{\mathrm{p}}=8 \mathrm{~ns}, f=10\right.$ $\mathrm{Hz}, E=1.4-145 \mathrm{~W} / \mathrm{cm}^{2}$ ) to modify the electrically evoked activity from spinal cords (Wesselmann et al., 1991a) as well as dorsal roots and peripheral nerves (Wesselmann et al., 1991b). In both studies, the compound action potential (CAP) amplitudes decreased, while the tissue temperature increased during irradiation up to $60^{\circ} \mathrm{C}$ (Wesselmann et al., 1994). In a different study, Orchardson et al. (1997) examined whether the inhibitory effect of a pulsed Nd:YAG radiation could be used for analgesia. Excised spinal nerves were irradiated ( $\lambda=1064 \mathrm{~nm}, \tau_{\mathrm{p}}=150 \mu \mathrm{s}, f=10-20 \mathrm{~Hz}, Q=30-150 \mu \mathrm{J} / \mathrm{pulse}$ ) to determine the laser parameters that blocked nerve conduction. They found a dose dependent decrease in compound action potentials of the nerve. Furthermore, the amplitude of the electrically evoked CAP was less likely to return to pre-irradiated levels for increasing laser power. The authors suggested that laser irradiation blocked the action potential (AP) propagation 
through the irradiated area of the nerve. The CAP latency decreased during irradiation, which was likely caused by an increase in tissue temperature.

Bagis et al. (2002) investigated the effect of a pulsed, Galium-Arsenide laser $(\lambda=904 \mathrm{~nm}$, $\tau_{\mathrm{p}}=220 \mathrm{~ns}, f=4-128 \mathrm{~Hz}, H=0.005-2.5 \mathrm{~J} / \mathrm{cm}^{2}$ ) on frog gastrocnemius muscles and sciatic nerves. The laser irradiation did not change electrical stimulation threshold, action potential latency, or duration.

A recent study has shown that irradiation with a pulsed, near-infrared diode laser $(\lambda=980$ $\mathrm{nm}, \tau_{\mathrm{p}}=4-400 \mathrm{~ms}, P=2.8-11 \mathrm{~W}$, spot size $=1.2 \mathrm{~mm}$ ) induced inward currents in dissociated cell cultures of nocioceptive rat dorsal root ganglion cells (Greffrath et al., 2002). At stimulation threshold fluence of $2.8 \mathrm{~J} / \mathrm{cm}^{2}$, they calculated a temperature of $42{ }^{\circ} \mathrm{C}$ at the neurons. Interestingly, the radiation-induced inward current decreased in amplitude with repeated stimulation. The authors suggested that the primary mechanism of stimulation was a thermal effect from the laser. Furthermore, they demonstrated that all of the laserstimulated neurons were sensitive to capsaicin, which is bound by a temperature-sensitive ion channel.

Hirase and coworkers (Hirase et al., 2002) imaged cortical cells with a two-photon fluorescence microscope. Irradiation with a pulsed Ti:Sapphire laser $\left(\lambda=790-850 \mathrm{~nm}, \tau_{\mathrm{p}}=\right.$ $130 \mathrm{fs}$ ), triggered action potentials (APs) without an exogenous fluorophore. Two regimes of optical stimulation were applied: Type-1 stimulation used laser powers of $200-400 \mathrm{~mW}$ and the underlying mechanism for stimulation likely involved a two-photon reaction with endogenous chromophores. Using exogenous fluorophore, irradiation with a wavelength longer than $800 \mathrm{~nm}$ could not stimulate neural tissue, whereas evoked responses always occurred when irradiation wavelengths were $790 \mathrm{~nm}$ or shorter. Type- 2 stimulation was achieved at higher radiation intensities. The authors hypothesized that the second type of stimulation resulted from microholes in the cell membrane, which allowed ion flux into the cell and subsequent neural depolarization.

\section{Optogenetics}

Optogenetics refers to the combination of optics and genetics to modulate the function of living cells. Years before optogenetics had been introduced to the field of neuroscience, bacteriorhodopsin, a light activated ion pump, has been identified (Oesterhelt and Stoeckenius, 1971; Oesterhelt et al., 1973). With the discovery of bacteriorhodopsin, other members of this microbial opsin family have been identified, including halorhodopsins, which transports chloride from the intracellular space (Oesterhelt and Krippahl, 1973; Matsuno-Yagi and Mukohata, 1977) and channelrhodopsins (Nagel et al., 2002; Nagel et al., 2003). In response to optical irradiation, Channelrhodopsin (ChR) showed ion flux across the membrane while halorhodopsin (HR) transports chloride from the intracellular space. In 2005 it has been first reported that channelrhodopsins can be expressed in mammalian neurons to control neural activity (Boyden et al., 2005). The term "optogenetics" was coined during this period. 


\section{Optogenetic tools}

The first optogenetic tools were the channelrhodopsins, which were light sensitive 7transmembrane proteins, and halorhodopsin. Performance of each of the opsins at the singlemolecule level is determined by the efficiency of the light absorption and the turnover time of the photocycle. Light absorption depends on the molar absorption coefficient, which is typically between 50,000 and $70,000 \mathrm{M}^{-1} \mathrm{~cm}^{-1}$ and the quantum efficiency, which is typically between 0.3 and 0.7 (Zhang et al., 2011). For most of the first reported optogenetic tools the photocycle turnover time is $10-20 \mathrm{~ms}$ capping temporal precision and maximum firing rate (see also Table 2). Grossman et al. $(2011 ; 2013)$ modeled the light-to-action potential conversion. In their 2011 paper they estimated the saturation characteristics for ChR2. The effective area over which a single ChR2 molecule absorbs a photon is $\sim 1.2 \times 10^{-8}$ $\mu \mathrm{m}^{2}$ (Hegemann et al., 2005). During irradiation with blue light at fluence rates of 1 $\mathrm{mW} / \mathrm{mm}^{2}$, which corresponds to $\sim 2.4 \times 10^{6}$ photons $/\left(\mathrm{ms} \mu \mathrm{m}^{2}\right)$, each ChR2 receives on average one photon every $40 \mathrm{~ms}$. Similarly, at $40 \mathrm{~mW} / \mathrm{mm}^{2}$, each ChR2 receives on average one photon every $1 \mathrm{~ms}$. Assuming that the channel remains open for about $10 \mathrm{~ms}$, sequential photon will encounter an already open channel that reduces the efficiency of the stimulation. It is not surprising that the early $\mathrm{ChR}$ directly evoked reliable spiking between $5-70 \mathrm{~Hz}$ (Boyden et al., 2005; Li et al., 2005; Ishizuka et al., 2006; Arenkiel et al., 2007; Moser et al., 2013), while many neuronal cells and physiological processes require higher spike repetition rates.

Efforts have been employed to develop optogenetic tools with faster response rates and different activation wavelengths. ChRs from different species can have different channel kinetics and spectral properties. Numbers of variants were identified from different bacteria, algae and fungi species (e.g., ChR1 and ChR2 families). Compare to VChR1 (from Volvox carteri), MChR1 (from Mesostigma viride) has a red-shifted spectrum and faster kinetics (Govorunova et al., 2011). Natural or artificial mutants are also studied intensely. Effective mutations, such as ChETA mutations (ChR E123T/A), often occur in ChR's retinal-binding pocket and require the involvement of multiple sites (for review, see Hegemann and Moglich, 2011). It has been shown that the removal of the putative proton acceptor in the E123 position leads to more rapid channel closing and enables optical control of spiking at least up to $200 \mathrm{~Hz}$ (Gunaydin et al., 2010). The smaller current of the ChETA can be compensated for by using more intense or longer light exposures. Domain swapping is another approach to generate chimera ChRs with kinetics different from the original constructs. Examples include ChRGR, ChEF and ChIEF, hybrids of ChR1 and ChR2 (Wang et al., 2009), and C1V1, a combination of ChR1 and VChR1. Excellent reviews on this topic have been published recently (Yizhar et al., 2011a; Zhang et al., 2011; Bernstein et al., 2012).

For novel optogenetic tools, it is desirable that the channels are more sensitive and have larger conductance. The latter goal can be achieved if response rate is not important. For fast responding optogenetic tools often the channel conductance and sensitivity are reduced. On the other hand, ChRs with extremely slow kinetics (seconds to minutes), such as ChR2/ C128X, can also find their application on inducing prolonged subthreshold depolarization 
(Berndt et al., 2009; Schoenenberger et al., 2009). These ChRs are also called "stepfunction" or "bistable" opsins.

Proton pumping opsins have also been found in marine proteobacteria with photocycles similar to bacteriorhodopsin. Interestingly, the action spectra of the marine proteobacteria are tuned to the ocean depth and latitude of their origin. Hence, it has been investigated whether the genomic background could explain the opsins' spectral tuning. For example, the absorption variance between blue and green radiation can depend on a single amino acid residue (Man et al., 2003). The question of how to shift the absorption spectrum towards the red or near-infrared is of importance for the light delivery. Visible light is little absorbed or scattered in air and water. The spot size at the target is then determined by size and emission characteristics of the light source and the optics between the source and the target. However, visible light is highly scattered in tissue, the penetration depth is decreased significantly, and the spot size is widened drastically. A good comparison for the differences in the photon distribution in water and in brain tissue is given in Yizhar (Yizhar et al., 2011a) and is reproduced in Figure 2. The "red-shift" could reduce the scatter of the photons and increase the penetration depth and selectivity of irradiation site in the tissue.

\section{Targeting strategies}

It is not only important to develop novel and optimize optogenetic tools for efficient transcription, expression and safety; strategies and tools must be developed to express the channels in selected target cells in vivo. Typically viral vectors are used to express the optogenetic tools.

Viral vectors-Adeno-associated viral vectors (AAV) or lentiviral vectors (LV) are used to deliver the optogenetic tool to the intact neural system (see also Table 3). AAV and LV as delivery tools have been successfully applied in mouse, rat, guinea pig, and primate (for a review see e.g. Yizhar et al., 2011a). These vectors have achieved high expression levels over long periods of time with little or no reported adverse effects. Today, the production of $\mathrm{LV}$ is a standard tissue culture technique. In contrast, AAV production is more challenging in standard laboratory environments, but AAV are considered safer than LV since currently available strains do not broadly integrated into the host genome. In the common laboratory setting AAVs are rated as BSL1, compared with BSL2+ for LV. While viral vectors target a broad selection of cells, cellular specificity of the vectors can be obtained by specific promoters (Yizhar et al., 2011a). From the list of promoters, which is available today, it also becomes evident that finding the most efficient promoter for expressing the optogenetic tool in a selected target cell type is challenging.

Transgenic animals-Different strategies have been used to express a gene in a targeted cell type. In the first approach the transgene is expressed directly under a promoter, which is active in only the target cell type. Following a pronuclear injection of the promoter transgene assembly into zygote eggs, the transgenic construct randomly integrates into the mouse genome. For the second approach, the expression of the transgene is regulated by "driver" gene, where the driver gene expression is controlled by a specific promoter. The challenge for expressing an optogenetic tool is the high-level of expression of those genes in 
the cells whose activity is to be manipulated in in vivo studies. Strategies of mouse transgenic approaches in optogenetics have been nicely presented by Zeng and Madisen (Zeng and Madisen, 2012). Successful creation of mouse lines, which express ChR2 have been reported (Arenkiel et al., 2007; Wang et al., 2007; Gradinaru et al., 2009; Sohal et al., 2009; Hägglund et al., 2010; Thyagarajan et al., 2010).

\section{Applications of optogenetics}

Ample examples are available to show that the different light sensitive ion channels can be expressed in target neurons and render them sensitive to light. Visible light of different color can be used to either stimulate or inhibit the neurons. At present, the majority of applications are to study and understand complex networks. In addition to addressing scientific questions, optogenetics has been implemented to control diseases or attempts to rehabilitate loss of neural function.

Non-auditory systems-In C. elegans, Channelrhodopsin-2 (ChR-2) was expressed in muscle cells to trigger the muscle contraction by blue or green light irradiation (Nagel et al., 2005; Akerboom et al., 2013). ChR-2 was expressed in Drosophila to study, activation of different neuron types that enabled the remote control of animal behavior. Optogenetic tools were also used in Drosophila to study specific neural circuits including sensory, modulatory intermediate and motor neurons (Zhang et al., 2007b). In zebrafish, precise control of neural activity with ChR-2 evoked distinct behaviors such as backward swimming (Zhu et al., 2009) and escape reflex (Douglass et al., 2008).

After the initial report of the expression of ChR-2 in mammalian neurons (Boyden et al., 2005; Li et al., 2005; Nagel et al., 2005; Ishizuka et al., 2006), genetically modified ChR molecules with better expression (e.g. Zhang et al., 2006) or faster dynamics (e.g. Gunaydin et al., 2010) were tested. Combining with transgenic mammalian animal models, novel applications of optogenetics blossomed in recent years (for review, see Yizhar et al., 2011a). Applications in study and understanding of complex networks, such as behaviors and neural circuits and their causal relationships, are still predominant (Matsui, 2013; Nelson et al., 2013; Stroh et al., 2013). For reviews, see (Zhang et al., 2007a; Zhang et al., 2010; Kokaia and Sorensen, 2011; Tye and Deisseroth, 2012). These applications mostly take advantage of the temporal precision and cell-type specificity of optogenetics, without which the study may become extremely difficult. Liu and colleagues targeted the dentate gyrus of c-fos-tTA transgenic mice with ChR2 to study the recall of a fear memory (Liu et al., 2012). The promoter of c-fos, a marker of recent neural activity, was used to drive the expression of tetracycline transactivator (tTA), which in turn induced the expression of the target gene ChR-2. Optical stimulation afterwards in dentate gyrus activated the ChR-2 expressing neurons, which recollected the freezing behavior evoked by fear memory. A following study showed that a false memory could be generated by optical reactivation of the neurons fired during fear conditioning (Ramirez et al., 2013). Chaudhury and others expressed ChR-2 in ventral tegmental area (VTA) dopamine neurons in mice through adenovirus vector (Chaudhury et al., 2013). Neurons in this area have different firing patterns and mediate stress responses. Temporal precision and cell-type specificity optical induction showed that, enhanced phasic firing instead of tonic firing in VTA dopamine neurons mediates 
depression-associated behaviors. Another study targeted the bed nucleus of the stria terminalis, the region modulating fear and anxiety, which also projected to VTA, using the same optogenetic construct (Jennings et al., 2013). The results showed that, the excitatory glutamatergic projections and inhibitory GABAergic projections both innervated nondopaminergic VTA neurons but with divergent motivational effects. In the lateral hypothalamus, the roll of hypocretin producing neurons in sleeping and awakening was investigated through transfection of ChR2 with a lentivirus vector (Adamantidis et al., 2007). Selective optical stimulation of these neurons facilitates the transition to wakefulness in a stimulation frequency-dependent manner. Light pulse trains at $5-30 \mathrm{~Hz}$, but not $1 \mathrm{~Hz}$, reduced the latency to wakefulness. Conditional halorhodopsin expressing transgenic mice model were generated (Imayoshi et al., 2013). Optical stimulation of the halorhodopsin expressing neurons induced a hyperpolarization on membrane potential and inhibited the firing of action potential. Attempts to control spontaneous seizures in a temporal lobe epilepsy mice were achieved through optogenetics (Krook-Magnuson et al., 2013). In this study the inhibitory halorhodopsin was expressed in the excitatory principal cells and excitatory ChR2 was selectively expressed in GABAergic inhibitory cells. Either way the frequency of spontaneous seizures were reduced significantly. Optogenetics is also widely employed in neocortex for network activities (Favero and Castro-Alamancos, 2013), motor cortex for optical control of type-specific neural activities (Aravanis et al., 2007) and corticocortical connections (Hira et al., 2013), and visual cortex for the studies such as multisensory integration (Olcese et al., 2013), spatial integration (Vaiceliunaite et al., 2013) and neurovascular coupling (Pisauro et al., 2013).

Other mammalian models and targeting tissues include rat (e.g., cardiac muscles, (Jia et al., 2011); cerebellum, (Tsubota et al., 2011); prefrontal cortex, (Chen et al., 2013) and nonhuman primates (Han et al., 2009; Tamura et al., 2012). In primate, the delivery of genecarrying vectors and optical stimulation system through the thick dura mater is a big challenge (Ruiz et al., 2013).

Auditory system-To study the cochlear amplifier and micromechanics of the cochlea Nuttall et al. expressed ChR2 in outer hair cells (OHCs). Their first results show that light pulses $\left(\lambda=473 \mathrm{~nm}, \tau_{\mathrm{p}}=100 \mathrm{~ms}, f=10-20 \mathrm{~Hz}, \varphi=1 \mathrm{~mW} / \mathrm{mm}^{2}\right)$ induced inward currents into the OHCs. The authors intend modulating the $\mathrm{OHC}$ membrane potential to change the driving force of the transduction current and subsequently control OHC somatic motility.

In a different approach, Moser et al. (2013) studied the possibility of using an optogenetic approach for cochlear prostheses. They used a mouse model expressing ChR2 in cochlear spiral ganglion neurons. Initial results showed that they could evoke spatially selective responses by irradiation with blue light. A comprehensive presentation of the data has recently been published (Hernandez et al., 2014). Transgenic mice were engineered, which express ChR2 in the somata, dendrites, and axons of SGNs. No ChR2 was found in cochlear hair cells. To test the ability to evoke cochlear responses, blue light was delivered either via the round window or a cochleostomy. Irradiation of the SGNs resulted in a measurable oABR for either of the stimulation configuration. Stimulation threshold was $2 \mu \mathrm{J} / \mathrm{mm}^{2}$ with a dynamic range for the responses of more than $20 \mathrm{~dB}$ (Hernandez et al., 2013; Moser et al., 2013; Hernandez et al., 2014). The minimal latency for the response was $3.1 \mathrm{~ms}$. Selectivity 
of the optical stimulation was demonstrated by the masking of acoustic responses using a light stimulus and by determining spatial tuning curves obtained from neural activity recorded from the inferior colliculus. The width of the spatial tuning curves was $475 \pm 65.5$ $\mu \mathrm{m}$ for optogenetic stimulation, which was smaller when compared to the width of the spatial tuning curves obtained during acoustic pure tone stimulation $(666.7 \pm 95.7 \mu \mathrm{m})$, or monopolar electrical stimulation $(828.6 \pm 101.7 \mu \mathrm{m})$. In addition to use transgenic animals, the authors also crossed the Thy1.2-driven $C h R 2$ transgene with $O{ }{ }^{\text {Pga/Pga }}$ mice to express $\mathrm{ChR} 2$ in their SGNs, to mimic a model to rescue from early onset of genetic deafness. The channel was also expressed in SGNs using a viral vector. Efficient and cell specific expression of the optogenetic tool was only observed for AAV2/6. Neural responses could be evoked by direct irradiation of the neurons up to $60 \mathrm{~Hz}$, the current limit of their stimulation setup (Hernandez et al., 2014).

Another group conducted short-term experiments in guinea pigs and rats to deliver ChR2 to the brainstem via a single injection of AVV. After a survival period of 2-3 weeks, the expression of $\mathrm{ChR} 2$ was examined. A broad pattern of expression of the channel was observed in the cochlear nucleus (Acker et al., 2011). Responses, which were evoked with a large diameter optical fiber, showed a broad pattern of excitation in the ICC similar to electric stimulation (Darrow et al., 2013a) or to an acoustic click (Darrow et al., 2013b).

The potential of optogenetics for the auditory system lays in its known mechanism. The optogenetic tool determines whether the target neuron is depolarized or hyperpolarized during irradiation. The challenges lay in the speed of the channels. Moreover, for visible light, tissue will significantly scatter the photons and selective stimulation will require the light source in close proximity to the target structure. In spite of powerful light sources, such as lasers or laser diodes, they are only available as single sources for the wavelengths used in optogenetics.

\section{Thermogenetics}

The term "thermogenetics" has been christened in a recent review by Bernstein et al. (2012) and describes the method of using molecular sensitizers that allow the modulation of neural activities by changes in temperature. In particular, two classes of candidates have been discussed, (1) the dominantly acting protein, Shibre ${ }^{\text {ts1 }}$, which inhibits endocytosis at temperatures above $\sim 29^{\circ} \mathrm{C}$ a nd likely affects synaptic vesicle recycling and chemical transmission, and (2) the class of temperature sensitive TRP (Transient Receptor Potential) channels that can be activated by a local increase in temperature (e.g. Caterina et al., 1997).

TRP channels have also been discussed as the target for neural stimulation in a different approach, infrared neural stimulation (INS). The channels are expressed ubiquitously in many target neurons and can be stimulated directly with infrared radiation (Suh et al., 2009; Yao et al., 2009; Albert et al., 2012). The channels can also be expressed in target cells and render them temperature sensitive. Yao et al. (2009) expressed Transient Receptor Potential Vanilloid 1 (TRPV1), TRPV2 and TRPV3 channels in HEK293 cells and successfully activated the channels with temperature jumps created with near infrared diode lasers $(\lambda=$ 980 and $1460 \mathrm{~nm})$. 
For the auditory system the presence of TRPV channels has been demonstrated in the cochlea and in the spiral ganglion neurons and provide a natural sensor for local heating. While it is convenient that the target for the radiation is already present, the use of the technique will be limited by the deposition of heat in the tissue. In particular, at repetition rates, which are typically required for the auditory system, heat will accumulate during the stimulation and may damage the tissue. The additional expression of the heat sensitive channels will render the neurons more sensitive to the temperature changes and will increase the maximum rate, at which light pulses can be delivered. At present only excitatory action could be mediated by temperature in those channels. It is not clear whether inhibition and excitation can be achieved at the same time.

\section{Optoacoustics}

The first report that light can produce sound was by Bell in 1880 (Bell, 1880). Today, optoacoustics describe a technique, in which light generates sound waves in gas or other medium (for an overview see e.g. Tuchin, 2000). After the target tissue has absorbed the photons, their energy is converted into heat, leading to rapid heating of the optical zone. The resulting thermoelastic expansion causes stress, which will propagate as a stress wave out of the optical zone into the tissue. Pressure waves are in particular large if the pulse duration is shorter than the propagation time for stress wave out of the irradiated zone. For pulse durations shorter than $1 \mu$ s the condition has been described as stress-confined (Tuchin, 2000; Niemz, 2004; Welch and van Gemert, 2012). Recently is has been reported that for pulse durations, which are orders of magnitude longer than $1 \mu \mathrm{s}$, audible stress wave can be generated as well (Teudt et al., 2011). It has been suggested that light induced pressure waves can be used to mechanically stimulate the cochlea (Wenzel et al., 2009; Zhang et al., 2009; Teudt et al., 2011; Schultz et al., 2012b; Schultz et al., 2012a).

In one approach, Wenzel and coworkers (Wenzel et al., 2009) used a Nd:YAG laser ( $\lambda=532$ $\mathrm{nm}, \tau_{\mathrm{p}}=10 \mathrm{~ns}, f=10 \mathrm{~Hz}$, the $Q=0-23 \mathrm{~J} /$ pulse) to stimulate the cochlea of guinea pigs. They were able to evoke auditory brain stem responses in hearing animals. The response could not be evoked in deaf animals. For radiation wavelengths in the near infrared, the responses correlated with the water absorption for the photons. Furthermore, a positive correlation for responses in the cochlea to optical stimulation occurred at $\lambda=600-800 \mathrm{~nm}$, the absorption coefficient of hemoglobin (Schultz et al., 2012b).

During optoacoustic stimulation, laser induced pressure waves vibrate the basilar membrane and stimulate hair cells. The hair cells are required to transform the acoustic signal into action potentials on the auditory nerve. Since the acoustic signal is similar to an acoustic click it is counterintuitive that the stimulation result in a selective stimulation of the cochlea. Nevertheless, it has been demonstrated that laser pulses in the infrared result in a focused pressure wave in front of the optical fiber (Teudt et al., 2011).

The important message from the experiments is that all stimuli at radiation wavelength in the infrared will generate stress relaxation waves and will heat the target volume. Considering the technique for scientific applications or for prosthetic means has to address and the issues of thermal damage and stress related effects. 


\section{Infrared neural stimulation}

\section{Stimulation of peripheral nerves}

Results from successfully stimulating the sciatic nerve and the nervus pudendus have been reported. In both cases the experiments have been performed in the rat animal model. To reduce the radiant energy for optical stimulation, electrical and optical co-stimulation has been investigated in aplysia californica and the rat sciatic nerve.

Sciatic nerve-Wells et al. (Wells et al., 2005a; Wells et al., 2005b) were the first to show that the rat sciatic nerve could be stimulated with pulsed infrared radiation, the Free Electron Laser (FEL). The radiant energy was deposited into non-manipulated neural tissue at optical wavelengths in the infrared. With the assumption that water is the sole absorber, the estimated optical penetration depth in neural tissue for these wavelengths is 200 to $1500 \mu \mathrm{m}$ (Rosenberg and Gunner, 1959; Falk and Ford, 1966; Hale and Querry, 1973; LoPachin and Stys, 1995). The results from Wells and coworkers showed that ablation thresholds scaled with the wavelength-dependent water absorption coefficient (see Figure 3 in Wells et al., 2005a), but the stimulation threshold did not. The largest energy ratios for ablation and stimulation was at wavelengths around 4 and $2.1 \mu \mathrm{m}$ (Wells et al., 2005a). In addition to the first measurement with the FEL ( $\left.\lambda=2000-6000 \mathrm{~nm}, \tau_{\mathrm{p}}=5 \mu \mathrm{s}, f=1-30 \mathrm{~Hz}\right)$, a Ho:YAG laser $\left(\lambda=2120 \mathrm{~nm}, \tau_{\mathrm{p}}=350 \mu \mathrm{s}, f=1-8 \mathrm{~Hz}\right)$, and a pulsed diode laser $\left(\lambda=1860 \mathrm{~nm}, \tau_{\mathrm{p}}=10\right.$ $\mu$ s to $10 \mathrm{~ms}$ ) were used. Similar stimulation of the sciatic nerve could be achieved with the latter lasers. Other researchers have investigated alternative wavelengths for infrared sciatic nerve stimulation, namely in the $1400-1600 \mathrm{~nm}$ range (McCaughey et al., 2010). They compared the Ho:YAG $(\lambda=2120 \mathrm{~nm})$, Yb:glass $(\lambda=1495 \mathrm{~nm})$, and two diode lasers $(\lambda=$ 1450 and $1540 \mathrm{~nm})$. Although nerve stimulation was achieved, the pulse durations to achieve depolarization were significantly longer $(\sim 100 \mathrm{~ms})$ and the fluences were higher than those demonstrated in previous experiments.

The advantage of using optical radiation over using electrical currents for neural stimulation is its spatial resolution (Wells et al., 2007a). Only neural tissue that is directly in the optical beam path will be stimulated. Wells et al. (2007a) found that irradiation of different portions of the sciatic nerve evoked contraction in different muscle groups.

Nervus pudendus-Rat cavernous nerves were stimulated with a thulium fiber laser $(\lambda=$ $1870 \mathrm{~nm} ; \tau_{\mathrm{p}}=2.5 \mathrm{~ms} ; f=10 \mathrm{~Hz}, Q=7.5 \mathrm{~mJ} /$ pulse) to test whether the method could be used as an alternative nerve mapping method to electrical stimulation during radical prostatectomy (Fried et al., 2008b; Fried et al., 2008a; Tozburun et al., 2010). Successful stimulation was determined by an intracavernous pressure response in the rat penis with the pressure returning to baseline values after stimulation. The authors demonstrated that stimulation occurred with the laser operating in either continuous wave mode (average radiant power up to $47.3 \mathrm{~mW}$ ) or in pulsed mode ( $\tau_{\mathrm{p}}=5 \mathrm{~ms} ; f=10-100 \mathrm{~Hz}, Q=0.56-4.8$ $\mathrm{mJ} / \mathrm{pulse})$. In addition to the thulium fiber laser, three other diode lasers $(\lambda=1455,1490$ and $1550 \mathrm{~nm}, P=0-100 \mathrm{~mW}(\mathrm{cw})$, spot size $=1 \mathrm{~mm}$ ) were tested for their potential to stimulate the nervus pudendus through an up to $450 \mu \mathrm{m}$ thick fascia. With increasing thickness of the 
fascia, larger radiant power was required to stimulate the nerve (Tozburun et al., 2012;

Tozburun et al., 2013).

Electrical and optical co-stimulation-Safety studies for INS using the rat sciatic nerve have shown that the radiant energy for sciatic nerve damage is at about twice the energy for stimulation (Wells et al., 2007c). Experiments in rat sciatic nerves and the buccal nerve of aplysia californica were conducted to determine whether the range for safe neural stimulation could be increased by electrical and optical costimulation. Initial experiments were conducted in the rat sciatic nerve. Duke et al. used a diode laser $\left(\lambda=1875 \mathrm{~nm} ; \tau_{\mathrm{p}}=2\right.$ $\mathrm{ms} ; f=2 \mathrm{~Hz}$ ) and delivered the radiant energy via a $400 \mu \mathrm{m}$ optical fiber. They showed that the threshold for INS could be reduced by a factor of $\sim 2$ with the simultaneous presentation of a sub-threshold electrical stimulus and a laser pulse (Duke et al., 2009; Duke et al., 2012). The interaction between electrical current pulses and INS was also studied in detail using the buccal nerves of aplysia californica with the Ho:YAG laser $\left(\lambda=2120 \mathrm{~nm}, \tau_{\mathrm{p}}=0.25 \mathrm{~ms}, f=\right.$ $2 \mathrm{~Hz})$ and a diode laser $\left(\lambda=1875 \mathrm{~nm}, \tau_{\mathrm{p}}=2-3 \mathrm{~ms}, f=2 \mathrm{~Hz}\right)$. Threshold fluence for INS was on average $1.12 \mathrm{~J} / \mathrm{cm}^{2}$ and could be lowered by about a factor of 2 . The results also demonstrated that finite regions of excitability exist. Polarity, amplitude, and phase of the biphasic electrical pulse could alter size and sensitivity for INS at those sites (Duke et al., 2012). The experiments also revealed that an increase in the radiant energy could result in an inhibition of a supra-threshold electrical pulse (Duke et al., 2012).

\section{Stimulation of cranial nerves}

Facial nerve-Gerbil facial nerves were stimulated with a pulsed Ho:YAG laser $(\lambda=2120$ $\mathrm{nm}, \tau_{\mathrm{p}}=0.25 \mathrm{~ms} ; f=2 \mathrm{~Hz}$ ) and were delivered via a $600 \mu \mathrm{m}$ diameter optical fiber (Teudt et al., 2007). Muscle action potentials and resulting whisker movements were monitored. Compound muscle action potentials (CmAPs) evoked with either optical radiation or electrical current were similar in shape. However, the onset of the optically-evoked CmAP was delayed relative to the electrical CmAP. Radiant exposures were between 0.71-1.77 $\mathrm{J} / \mathrm{cm}^{2}$ and evoked CmAPs that were simultaneously measured at the facial muscles (m. orbicularis oculi, $\mathrm{m}$. levator nasolabialis, and $\mathrm{m}$. orbicularis oris). To determine acute damage thresholds, nerve samples were examined. Histology showed tissue damage at fluences of $2.2 \mathrm{~J} / \mathrm{cm}^{2}$, but no apparent damage at radiant exposures of $2.0 \mathrm{~J} / \mathrm{cm}^{2}$. Spatial selectivity of infrared nerve stimulation has been demonstrated in these experiments at the facial nerve trunk.

Auditory nerve-At present, INS of the auditory nerve has been studied in the gerbil, the mouse, the guinea pig and the cat. Experiments were done in hearing, acutely deafened and chronic deaf animals. Following the deafening procedure, the animals showed significant elevation in hearing threshold for high frequencies, at the tonotopically correspondent site of the optical fiber placement. Despite the loss of hearing for high frequencies, the animals had variable residual hearing for low frequencies. In gerbils, a Ho:YAG laser $\left(\lambda=2.12 \mu \mathrm{m}, \tau_{\mathrm{p}}=\right.$ $250 \mu \mathrm{s}, f=2 \mathrm{~Hz}, Q=0-127 \mu \mathrm{J} /$ pulse) was used to stimulate the auditory nerve (Izzo et al., 2006). The laser was coupled to a $200 \mu \mathrm{m}$-diameter optical fiber, which was placed in front of the cochlear round window. The optical beam was directed towards the spiral ganglion 
cells. CAPs were evoked in response to the laser pulses. An increase in radiation energy induced a monotonic increase in the evoked response. Subsequent experiments with different Aculight diode lasers ( $\lambda=1844-1940 \mathrm{~nm}, \tau_{\mathrm{p}}=5 \mu \mathrm{s}-1 \mathrm{~ms} ; f=2-1000 \mathrm{~Hz}$ ) showed that the patterns of the CAPs changed with increasing pulse duration (Izzo et al., 2007b; Izzo et al., 2008). The variability in the input-output curves was, in part, due to differences in the physiological state of each animal and differences in optical fiber placement. In acutely deafened and in chronically deaf gerbils, thresholds for optically evoked CAPs were not significantly elevated when stimulating with short pulse durations (Richter et al., 2008).

In addition to compound action potentials, the responses of single auditory nerve fibers were recorded during optical stimulation. The recordings from low-spontaneous- rate neurons showed on average a firing efficiency of $\sim 40 \%$ at $200 \mathrm{~Hz}$ laser stimulation rate (Littlefield et al., 2008).

Auditory nerve - spatial selectivity-Spatial selective stimulation of the auditory nerve was possible. Three series of experiments were conducted to characterize the spatial selectivity for INS in the cochlea, (1) immunohistochemical staining for c-Fos (Izzo et al., 2007a), (2) tone-on-light masking (Matic et al., 2011), and (3) recording of neural responses in the inferior colliculus and constructing corresponding spatial tuning curves (Richter et al., 2011).

The transiently expressed transcription factor, c-Fos, was used to stain activated nerve cells and to identify the spatial area of the cochlea that was stimulated with a Ho:YAG laser $(\lambda=$ $2.12 \mu \mathrm{m}, \tau_{\mathrm{p}}=350 \mu \mathrm{s}, f=2 \mathrm{~Hz}, H=60 \mathrm{~mJ} / \mathrm{cm}^{2}$ ), which was coupled to a $100 \mu \mathrm{m}$ optical fiber. The optical fiber was approximated to, but not penetrated, the round window membrane and was visually oriented toward the spiral ganglion cells. Immunohistochemical staining for c-Fos in the cochlea showed a small area of optical stimulation, which occurred directly opposite to the optical fiber (Izzo et al., 2007b). This pattern of c-Fos labeling is in contrast to that after electrical stimulation. Electrical stimulation leads to a large, more spatially extended population of labeled, activated neurons.

Spatial selectivity has also been measured with a masking method (Matic et al., 2011). Laser pulses with fixed optical parameters were delivered with a $200 \mu \mathrm{m}$ optical fiber and were presented simultaneously with an acoustic tone. The tone was variable in frequency and level. Tone-on-light masking in gerbils revealed tuning curves with best frequencies between $5.3-11.2 \mathrm{kHz}$. The width of the tone-on-light tuning curves was similar to the width of tone-on-tone tuning curves. The results indicate that the spatial area of INS in the gerbil cochlea is similar to the cochlear area excited by a low level acoustic tone, showing promising results for future use of INS in implantable cochlear prostheses (Matic et al., 2011).

The spatial selectivity of INS in the acutely damaged cochlea of guinea pigs was determined from neural activity recorded in the ICC during INS (Figure 3). Results obtained with INS were compared to stimulation with acoustic tone pips in normal hearing animals. For the measurements, the radiation was delivered via a $200 \mu \mathrm{m}$ - diameter optical fiber, which was 
inserted through a cochleostomy into the scala tympani of the basal cochlear turn. ICC responses were recorded in response to cochlear INS using a multichannel penetrating electrode array. Spatial tuning curves were constructed from the responses. The majority of ICC spatial tuning curves indicated that the spread of activation evoked by optical stimuli is comparable to that produced by acoustic tone pips. In a recent study, a pulsed $808 \mathrm{~nm}$ pulsed infrared laser was used to stimulate the guinea pig cochlea (Xia et al., 2013).

The challenge for INS in the cochlea is the missing understanding of the mechanism. The agreeable fact is the heating of the target structure. Deposition of heat, however, has the risk of heat accumulation and subsequent tissue damage. This is particular a challenge for stimulation in the cochlea. While the scatter of infrared radiation by tissue is at least an order of magnitude smaller than for visible light the photons are absorbed over a much shorter distance. In other words, large distances between the stimulation source and the target tissue increase the risk for tissue heating. Heating of the target volume also results in stress relaxation waves that can result in audible acoustic events. Data are available that argue that the mechanism of INS is a pure acoustic event that stimulates remaining hair cells. Other data does not support the view that the INS is based on a mechanical stimulation of the hair cells (Kadakia et al., 2013; Young et al., 2014). However, the latter experiments do not rule out the direct interaction between the radiation and the hair cells as described for the vestibular system. The true potential of the technique for scientific questions and for potential prosthesis will require the full understanding of the mechanism of the stimulation.

Vestibular nerve-Vestibular prostheses, based on electrical stimulation, are currently being studied as a means to reduce imbalance and disorientation caused by vestibular dysfunction. However, electrically based vestibular prostheses suffer from current spread, which can lead to stimulation of unintended semicircular canal(s) and subsequently encode incorrect sensory information. Optical stimulation of the vestibular system has been investigated as a means to overcome the spread of electric current. Harris and coworkers (Harris et al., 2009) studied whether infrared radiation could be used to evoke neural activities from the vestibular nerve. Optical radiation at $1840 \mathrm{~nm}$ wavelength $\left(\tau_{p}=10 \mu \mathrm{s}-1\right.$ ms) was effective at evoking neural responses from the eighth nerve at a location where vestibular and auditory fibers were present. Power levels as low as $200 \mathrm{~mW}$ evoked a response. Direct irradiation of the ampullae produced an evoked potential at the maximum radiation energy obtained from the diode laser. However, optical stimulation of the ampullae did not evoke detectable eye movements.

In addition to the eighth nerve, they also stimulated the facial nerve. Careful inspection of the optically evoked facial nerve CAPs reveals a component at the onset of the optical pulse and at the offset of the pulse (Harris et al., 2009). The two CAP components became obvious with increasing time between the pulse onset and offset (longer pulse durations). Although offset responses have not been reported by others for the facial nerve or the sciatic nerve, they could be seen in some auditory neural responses. Experiments have yet to be conducted to determine the source of the offset response.

In a different set of experiments, Bradley stimulated Scarpa's ganglion in gerbils with diode lasers $\left(\lambda=1844-1877 \mathrm{~nm} ; \tau_{\mathrm{p}}=5 \mu \mathrm{s}-1 \mathrm{~ms} ; f=2-1000 \mathrm{~Hz}, Q=0-127 \mu \mathrm{J} / \mathrm{pulse}\right)$, while 
recording activities from single vestibular nerve fibers. The experiments showed an evoked compound action potential but did not result in detectable changes of single fiber activities.

Recently it has been shown that INS can activate vestibular hair cells (Rajguru et al., 2010a; Rajguru et al., 2010b). In experiments conducted in toadfish, Opsanus tau, horizontal semicircular canal afferents elicited a mix of inhibitory and excitatory responses evoked by stimulation directed towards the neuroepithelium housing the sensory hair cells. In a subset of afferents, the discharge rate reduced with irradiation, while in other afferents the discharge rate increased. A smaller subset of afferents displayed a mixed response comprised of an onset inhibitory response followed by an excitatory phase with tonic stimulation. The time course for the excitatory phase of the mixed units was similar to that of the excitatory afferents. The excitatory versus inhibitory afferent responses may correlate with the dynamic adaptive properties of afferent responses observed during mechanical stimulation (Rabbitt et al., 1995). Primary semicircular canal afferents in the toadfish are known to receive convergent inhibitory (GABA) and excitatory (glutamate) synaptic input from hair cells that ultimately shape the afferent discharge response (Holstein et al., 2004a; Holstein et al., 2004b). Data from those studies indicated that afferents receiving glutamatergic inputs may increase their discharge rate with INS. This is consistent with depolarization of hair cells and increased tonic release of glutamate. On the other hand, afferents that synapse on combinations of Glutamatergic and GABAergic hair cells were observed to reduce their discharge rate with INS.

The results obtained in the fish have been confirmed in the chinchilla (Boutros et al., 2013). Since these single unit responses included a mix of large excitatory, inhibitory, and mixed responses from canal afferents it is unclear whether infrared stimulation can evoke significant vestibulo-ocular reflex (VOR) eye movement responses. Experiments were conducted to test whether a robust VOR can be evoked with INS. Initial results of INS ( $\lambda=$ $1870 \mathrm{~nm} ; \tau_{\mathrm{p}}=200-350 \mu \mathrm{s}, f=200-400 \mathrm{~Hz}$ ) in the chinchilla demonstrate eye movements during IR stimulation in about 50\% of the animals (Boutros et al., 2013).

Despite the fact that studies show vestibular neural responses to INS, no study has yet demonstrated that the stimulation is selective. It may be that the Crista ampullaris, the sensory organ of the vestibular system, is insensitive to optical stimuli and/or that optical radiation stimulates remote afferent dendrites of the vestibular nerve. Although optical stimulation of the vestibular system nerve appears feasible, it has not been demonstrated that stimulation of afferent nerve fibers from individual canals can be achieved once they have collected in the nerve trunk.

\section{Stimulation of different brain structures}

Cortex-While peripheral nerves and cranial nerves have been successfully stimulated with infrared lasers, it appears more complicated to stimulate brain structures. Results on successful stimulation of the rat somatosensory cortex have been published (MahadevanJansen et al., 2010; Cayce et al., 2011). They placed a $400 \mu \mathrm{m}$ diameter optical fiber to stimulate the somatosensory cortex of anesthetized rats using an infrared diode laser $(\lambda=$ $\left.1875 \mathrm{~nm} ; \tau_{\mathrm{p}}=250 \mu \mathrm{s} ; \mathrm{f}=50-200 \mathrm{~Hz}, H=0.01-0.55 \mathrm{~J} / \mathrm{cm}^{2}\right)$. Results from intrinsic optical imaging and neural responses, which were recorded with tungsten electrodes from some 
units, were used to quantify the effects of INS. INS evoked an intrinsic response of similar magnitude to that evoked by tactile stimulation. The intrinsic signal magnitude increased with faster laser repetition rates and increasing radiant exposures. Neuronal firing of single unit recordings decreased and differed from that observed during tactile stimulation.

Similar experiments were conducted in non-human primates to stimulate the visual cortex (Cayce et al., 2013). INS evoked localized neural responses. At this cortical location, single unit neural activity increased during INS. Again, neural responses from single units was recorded with tungsten electrodes.

Stimulation of the auditory system-A different set of experiments was designed to test whether INS of the central auditory system is possible (Lee et al., 2009; Lee et al., 2011; Verma et al., 2014). In acute animal experiments, a $400 \mu \mathrm{m}$ diameter optical fiber was placed on the surface of the cochlear nucleus to irradiate the tissue with a diode laser $(\lambda=$ $1849-1865 \mathrm{~nm} ; \tau_{p}=5 \mu \mathrm{s}-10 \mathrm{~ms} ; \mathrm{f}=2-1000 \mathrm{~Hz}$ ). Auditory brainstem responses were recorded in hearing animals, which resembled a multi-peaked ABR evoked by acoustic stimulation. Blocking the optical path or euthanizing the rat eliminated the oABR.

Sectioning of the auditory nerve resulted in a significant decrease of the evoked response. The authors concluded that the response to INS was caused by an acoustic event that stimulated the cochlea (Verma et al., 2014).

\section{Stimulation of other preparations}

Other researchers working towards an all-optical stimulation and recording system have used an in vitro preparations of lobster nerves. To stimulate the nerves, they irradiated the tissue with $0.4-2 \mathrm{~ms}$ pulses at $1850 \mathrm{~nm}$ (Wininger et al., 2009). However, longer pulse durations allowed only $2-4$ repetitions of laser irradiation before nerve damage occurred. Readers should take caution in directly comparing these data with previous data because the energy output of the optical fiber and the spot size on the tissue were not reported.

Pulsed laser light can also stimulate cultured cardiomyocytes (Nathan et al., 1976; Smith et al., 2008; Dittami et al., 2011). Irradiation of the cardiomyocytes results in a depolarization of the cells and in a visible contraction. In an in vivo preparation, the pulsed infrared laser light $\left(\lambda=1875 \mathrm{~nm}, \tau_{\mathrm{p}}=1 \mathrm{~ms}, f=2-3 \mathrm{~Hz}, H=0.92 \mathrm{~J} / \mathrm{cm}^{2}\right)$ was used to lock the heart rate to the pulse frequency of the laser. At low radiant exposures, embryonic quail hearts were reliably paced in vivo without detectable damage to the tissue, indicating that optical pacing has great potential as a tool to study embryonic cardiac dynamics and development. In particular, optical pacing can be used to control the heart rate, thereby altering stresses and mechanically transduced signaling (Jenkins et al., 2010).

\section{Safety of cochlear INS}

In the cochlea, at high stimulation rates and high pulse energies, INS bears the risk of thermal damage to the tissue from either the instantaneous temperature increase or from potential accumulation of thermal energy. Longterm acute stimulation was tested in the cochlea in several experiments. Stimulation for 6 hours in the gerbil at $200 \mathrm{~Hz}$ stimulation rate showed stable CAP amplitudes for the duration of the stimulation (Izzo et al., 2006; 
Izzo et al., 2007b). Similar results have been shown in the cat (Rajguru et al., 2010c). While the laser parameter for the first two sets of the experiments were selected that no damage occurs, another series of experiments was conducted to determine the threshold for damage. No functional or histological damage in the cochlea was observed for up to 5 hours of continuous irradiation if the selected laser parameters for INS were: $\lambda=1869 \mathrm{~nm} ; \tau_{p}=100$; f $\leq 250 \mathrm{~Hz}$; Q $\leq 25 \mu \mathrm{J} /$ pulse (Goyal et al., 2012). Functional loss was observed for radiant energies above $25 \mu \mathrm{J} /$ pulse. Corresponding cochlear histology from control animals and animals exposed to 98 or $127 \mu \mathrm{J} /$ pulse at $250 \mathrm{~Hz}$ pulse repetition rate did not show loss of spiral ganglion neurons, hair cells, or other soft tissue structures of the organ of Corti. Light microscopy did not reveal any structural changes in the soft tissue either. Note, the cochleae were harvested directly after the exposure with no time for neural degeneration or structural changes to establish (Goyal et al., 2012).

The first longterm study was conducted in cats. Recently, a population of animals was chronically implanted with an optical fiber for INS. Behavioral responses of the cats indicated that stimulation occurred and a perceptual event resulted (Matic et al., 2013). Six weeks of stimulation of the cochlea, $6 \mathrm{~h}$ per day, with a fixed set of laser parameters $\left(\lambda=1850, \tau_{\mathrm{p}}=100 \mu \mathrm{s}\right.$, rate $\left.=200 \mathrm{~Hz}, \mathrm{Q}=12 \mu \mathrm{J} / \mathrm{pulse}\right)$ did not change the electrophysiological responses, either optically-evoked or acoustically-evoked. Spiral ganglion neuron counts and post implantation tissue growth, which is localized at the optical fiber, were similar in chronically stimulated and sham implanted cochleae (Matic et al., 2013).

\section{Mechanisms for stimulation with light}

For optogenetics and thermogenetics a chromophore exists that absorbs the photons and result in an excitation or inhibition of the cell. For optoacoustics an audible pressure wave is generated by the photon absorption and conversion into heat. Advances in finding the mechanism for INS have been made (Katz and Dalva, 1994; Wells et al., 2007b; Rhee et al., 2008; Feng et al., 2010; Rajguru et al., 2010a; Rajguru et al., 2010b; Dittami et al., 2011; Albert et al., 2012; Shapiro et al., 2012). However, the entire sequence that occurs between the delivery of the laser pulse and the neural response is not known. Laser-tissue-interaction is complex and is determined by the laser parameters and the tissue properties. Spot size, radiation wavelength, pulse duration, pulse repetition rate, and radiant energy for example characterize the laser properties, while absorption and scattering are important tissue properties. Photochemical, photothermal, and photomechanical interactions must be considered (for review see e.g. Jacques, 1992). Wells et al. (2007b) studied which of the aforementioned interaction may explain INS.

Photochemical reactions-A photochemical interaction occurs, if a molecular chromophore absorbs the photon (Jacques, 1992). The energy of the photon is converted into chemical energy. The molecular chromophore may be endogenous, such as amino acid groups, peptides pigments amino acids or might be exogenous molecules, which were introduced in to the tissue. Following experiments by Arvanitaki and Chalazonitis (1961) and Fork (1971), Faber and Grinvald (1983) systematically synthesized a photosensitive molecule that bound to the nerve membrane. After staining with the compound, neurons could be depolarized through irradiation with a He-Ne laser $\left(\lambda=632.8 \mathrm{~nm}, \tau_{\mathrm{p}}=\mathrm{up}\right.$ to $5 \mathrm{~s}$, 
$P=11 \mathrm{~mW})$. Their results suggested that laser stimulation occurred via transient, lightinduced channel activation that was not ion-specific(Farber and Grinvald, 1983). The photostimulation often caused irreversible photochemical damage to the nerves.

Photochemical neural activation can also involve the addition of a "caged" molecule that is released upon irradiation. Caged molecules are molecules that were rendered inert by chemically modifying the structure of a bioactive molecule. Irradiation transforms and/or cleaves the caged molecule to restore the biological activity, which is commonly referred to as "photorelease" or "uncaging" (Kao, 2006). The resulting active molecules can be agonists or antagonists. Thus, photolysis of caged compounds is a method for using light to switch biological processes on or off. In 1990, Wilcox and coworkers reported the synthesis of light-sensitive precursors to neurotransmitters (Wilcox et al., 1990). Dalva and Katz (Dalva and Katz, 1994; Katz and Dalva, 1994) used this technique to map the developing synaptic connections in the primary visual cortex of ferrets by uncaging photolabile glutamate. Since then, many investigators have taken advantage of these photolabile neurotransmitter precursors, most notably glutamate, in their research (for a review see Callaway and Yuste, 2002; Eder et al., 2004).

More recently, novel neurophysiologic approaches have been introduced that control ion channels and subsequently neural activity optogenetically and thermogenetically (Bernstein et al., 2012). The absorption of photons by a chromophore and the subsequent activation of ion channels is used in optogenetics to manipulate neurons. Depending of the optogenetic tool, excitation of inhibition can be achieved. Since inhibition and excitation is possible, the technique can be used to study and change the dynamics of neural networks.

It is unlikely that pulsed, mid-infrared lasers, such as the FEL, Ho:YAG, or Aculight diode lasers, evoke neural responses via a photochemical reaction. The photon energies emitted by these lasers are significantly lower than the energies required to move an electron to an excited state, as is needed for a photochemical reaction. For example, the energy in individual photons from the Ho:YAG is $\sim 0.58 \mathrm{eV}$. The value corresponds to a $\sim 52 \mathrm{~kJ} / \mathrm{mol}$ bond energy. Typical ion bond energies are larger, and are in the range of $100-1000 \mathrm{~kJ} / \mathrm{mol}$. Furthermore, data from Wells et al. did not identify a particular wavelength between 2 and $10 \mu \mathrm{m}$ at which the laser stimulation was significantly enhanced, which would have suggested a photochemical reaction (Wells et al., 2007b).

Photomechanical reactions-For photomechanical effects, both laser-induced stress waves and volumetric thermal expansion were considered as a mechanism for stimulation. Wells et al. (Wells et al., 2007b) measured cell surface displacements, which could be attributable to heat-induced volumetric expansions, using differential phase optical coherence tomography (DP-OCT). Furthermore, they created a piezo-electrical probe to indent the cells surface and to separate laser-induced temperature effects from volumetric stress waves. Pressure measurements with a needle hydrophone, revealed values below 1 bar. From their experiments they argued against a photomechanical mechanism from stress wave generation. 
Laser induced pressure waves in water are well documented for experiments with high local absorption. Pulsed $1850 \mathrm{~nm}$ laser light generates a measurable pressure (Teudt et al., 2011; Schultz et al., 2012b; Schultz et al., 2012a). Teudt et al. (2011) reported that for the laser's maximum energy levels and with a $200 \mu \mathrm{m}$ diameter optical fiber, the peak-to-peak sound pressure can reach $62 \mathrm{~dB}$ SPL in air. Since the cochlea is filled by endo- and perilymph, it is of interest to what extent laser induced sound waves exist when the absorbing volume is significantly decreased by immersion in water. Measurements in a swimming pool showed that radiant exposures of $0.35 \mathrm{~J} / \mathrm{cm}^{2}$ generated a pressure of $31 \mathrm{mPa}$ in water.

It has been stated that the energy required for a primary photomechanical mechanism is much higher than used by Wells et al. (Wells et al., 2007b) and Izzo et al. (Izzo et al., 2006). Valid arguments include that the parameter space of INS is outside of stress confinement. Stress confinement occurs when the optical energy accumulates in the tissue before a laserinduced stress wave can propagate out of the irradiated area, leading to large stress waves. For stress confinement to occur when irradiating with these wavelengths, the pulse duration should be shorter than $500 \mathrm{~ns}$, which is orders of magnitudes shorter than the pulse durations used for optical stimulation. On the other hand, results have been indicating that INS in the cochlea is dominated by a mechanical event and the stimulation of remaining hair cells (Baumhoff et al., 2013). The discrepancies have not completely resolved at this point.

Photothermal reactions-An alternative mechanism for INS could be the direct activation of heat-sensitive ion channels, which are present in nerves. The channels are termed the transient receptor potential (vanilloid) or TRPV channels (Caterina et al., 1997; Harteneck et al.; Güler et al.; Montell). TRPV1 is perhaps most well-known for being activated by the chemical capsaicin, the main ingredient in hot chili peppers that produces a burning sensation. TRPV1 channels are also stimulated by other vanilloid compounds, acid $(\mathrm{pH} \leq 5.9)$, and heat $\left(\geq 43^{\circ} \mathrm{C}\right)$, making it a key channel in peripheral nociception. TRPV channels are found in small neurons, including the sciatic nerve, the dorsal root and trigeminal ganglia of rats (Caterina et al., 1997), as well as cochlear structures of both the rat and guinea pig (Balaban et al., 2003; Zheng et al., 2003; Takumida et al., 2005; Suh et al., 2009) and have been identified in vestibular neurons (Albert et al., 2012).

Rhee et al. (2008) stimulated cultured primary sensory neurons from the inferior ganglia of rat with near-infrared radiation, which was delivered with a $200 \mu \mathrm{m}$ silica fiber coupled the output of an $1850 \mathrm{~nm}$ pulsed diode laser. The neurons express the vanilloid transient receptor ion channel (TRPV1), which is a non-selective cation channel that opens in response to temperature changes. Still, TRPV1 channels have an approximate 10:1 higher affinity to calcium than to sodium. Therefore, the authors monitored the intracellular calcium concentration using the fluorescent calcium indicator fura- 2 to monitor responses to INS. Brief trains of 2-ms IR pulses ( $\sim 5 \mathrm{~W}$ instantaneous power) activated the TRPV1 ion channels rapidly and reversibly. Identical INS did not increase intracellular calcium in the absence of extracellular calcium or after the application of a TRPV1 channel blocker.

Albert et al. suggested that TRPV4 channels mediate the infrared laser evoked response in sensory neurons. They conducted whole cell patch-clamp recordings and showed that voltage gated calcium and sodium channels contribute to a laser-evoked neuronal voltage 
variation. The application of micromolar concentrations of ruthenium red and RN 1734 suggested that the TRPV channels are the primary effectors of the chain reaction triggered by mid infrared laser irradiation.

A different view was presented by (Feng et al., 2010). Whole cell recordings were conducted on cultured rat cortical neurons while the cells were irradiated with a pulsed diode laser ( $\left.\lambda=1850 \mathrm{~nm}, \tau_{\mathrm{p}}=2 \mathrm{~ms}, f=30 \mathrm{~Hz}, Q=0.1 \mathrm{~mJ} / \mathrm{pulse}\right)$. During exposure the amplitude of spontaneous postsynaptic currents (SIPSCs) increased and the sIPSC decay accelerated (Feng et al., 2010). sIPSCs disappeared after the application of the $\mathrm{GABA}_{\mathrm{A}}$ receptor blocker bicuculline and could not be evoked by stimulation with the laser.

Whole cell recordings of dorsal root and nodose ganglion neurons showed that depolarizations evoked by INS has multiphasic kinetics comprising fast and slow components (2010). For their experiments they irradiated the neuron cultures with 5-10 ms pulses of $\lambda=1889 \mathrm{~nm}$. They found a near-uniform distribution of responsive neurons increased membrane conductance, and the negative reversal potential value $(-41 \pm 2.9 \mathrm{mV})$ and suggests that INS is unrelated to the activation of heat-sensitive TRPV1 channels. The long duration of the responses to INS favor an involvement of second messengers.

In a different study it has been demonstrated that infrared light excites cells through a novel, highly general electrostatic mechanism. Infrared pulses are absorbed by water, producing a rapid local increase in temperature. This heating reversibly alters the electrical capacitance of the plasma membrane, depolarizing the target cell. This mechanism is fully reversible and requires only the most basic properties of cell membranes (Shapiro et al., 2012).

The findings by Shapiro are supported by a recent study, which initial results show that pulsed infrared radiation rapidly alters the capacitance of the membrane through charge redistribution, and evokes mitochondrial $\mathrm{Ca}^{2+}$ currents (Liu et al., 2013). Although causality has not been shown, present results are consistent with the hypothesis that these biophysical events underlie infrared entrainment of miniature postsynaptic currents (mPSCs). Several authors discussed previously the crucial role of mitochondria and calcium ions in the mechanism for INS (Rajguru et al., 2010b; Dittami et al., 2011). In a recent series of experiments it has been shown that pulsed infrared consistently evoked calcium related responses in neurons (Lumbreras et al., 2013).

\section{Modeling of INS}

INS has been tested in many neural systems. However, laser parameters differ largely for stimulation among the different systems. An approach to explain differences could come from modeling of INS. Thompson at al. (Thompson et al., 2012) developed a Monte Carlo model to simulate light transport and absorption in tissue during INS. The compared the results from their modeling to the results obtained from INS in the cochlea. The results of the modeling suggest that the optimal optical fiber $(\mathrm{NA}=0.22)$ for INS has a diameter of 200 $\mu \mathrm{m}$. The model also predicts a temperature rise at the spiral ganglion of $0.1^{\circ} \mathrm{C}$. This temperature rise is similar to what has been previously estimated from INS in the gerbil cochlea (Izzo et al., 2008). Thompson at al. also used their model to study the temporal effects of heating during INS (Thompson et al., 2013b). Their model predicts two regimes of 
action: (1) for pulse durations up to100 $\mu$ s a pulse energy limited regime and for pulses longer than $100 \mu$ s a temperature gradient limited regime. The model was also used to determine the influence of the distance of the stimulation sources and the stimulus repetition rates on the local heating. With the assumption that the stimulus is delivered at $250 \mathrm{~Hz}$, INS in the cochlea will lead to a local temperature increase of about $2.3^{\circ} \mathrm{C}$. The calculation was done $\mathrm{f}$ or one stimulation site. When multiple stimulation sites are used, the temperature increase depends on the spacing between the stimulation sources. With the assumption that the light sources are separated by $750 \mu \mathrm{m}$, it has been predicted by the model that an additional 20\% increase in temperature will occur over the temperature increase of a single light source (Thompson et al., 2013a).

In a different approach, a model was created using multiphysics software from COMSOL to model the change in temperature and the temperature distribution during irradiation with an infrared laser at $\lambda=1550 \mathrm{~nm}$ radiation wavelength (Liljemalm et al., 2013). The model considers conduction and conviction for heat transport. Results show that the distribution is complex and nonlinear. The maximum rise in temperature and the temperature distribution depended on the fiber size, the pulse repetition rate and the radiant energy. When compared to published data, the model predicted low temperatures measured Shapiro et al. (Shapiro et al., 2012). A temperature accumulation was observed for repetitive stimulation.

In a recent paper by Norton et al. (Norton et al., 2013), an analytical approach has been used to determine the heat distribution and thermal criteria for INS. A solution for the heat diffusion equation was combined with the optical fluences. The developed framework could well be applied to existing experimental data. A key conclusion that has been drawn from the model is that the rate in temperature change and not the absolute temperature are essential for INS (Norton et al., 2013).

\section{Considerations for light-based neural prosthesis}

Despite results obtained from animal models showing that cochlear responses can be evoked with light after sensitizing the neurons with an optogenetic tool or stimulating cochleae with residual hearing with INS, it is not completely clear how a prosthesis based on light can be realized in the near future and whether it will improve contemporary technology. Electrical stimulation requires about 10 times less energy per pulse to evoke an action potential than optogenetic approaches have reported (Hernandez et al., 2014) and electrical stimulation is about 100 times less than INS would require. It has to be shown that the potential increase in the number of perceptual channels in an optical implant outweighs the additional energy required for stimulation.

The goal for neuroprostheses is to restore neural function to the fidelity of a healthy system. Contemporary neural prostheses aim to achieve this via electrical stimulation of the remaining neurons. Despite the research advances and clinical implementation of neuroprostheses, there are several challenges that neurostimulation faces (for a review see Grill et al., 2009). One of the main hurdles for neuroprostheses is achieving spatially and temporally selective stimulation. It has been argued that optical methods could improve spatial selectivity and increase the fidelity of implants. However, before implementing a 
prosthesis using photons, several design considerations must be made regarding the optical source and the light delivery system, in particular for the auditory system (see also Table 4). The light source should be able to deliver radiation pulses at least at $200 \mathrm{~Hz}$ with precise temporal control the pulse delivery and the light power. For optogenetic applications light sources with sharp spectral tuning at the activation wavelength of the optogenetic tool is required because microbial opsin-derived tools can be deactivated by light of wavelengths near the activation wavelength (Berndt et al., 2009). Moreover, if more than one optogenetic tool is used the sharp tuning of the stimulation source is critical that no overlap in stimulation occurs. For prostheses, the light sources cannot be large devices but must be miniaturized, still achieving sufficient light output. Light sources are typically lasers or LEDs. Lasers are an appealing option for either of the discussed approaches. They typically have a narrow spectral line-width, which can be matched to the activation wavelength of the optogenetic tool, they typically deliver optical pulses with the required power to evoke a neural response, and they can be modulated at high frequencies. While lasers are ideal for bench top experiments, they pose a challenge for prosthetics. Laser diodes are significantly smaller than tabletop devices but they would still be too big to be implanted close to neural structures, in particular in the cochlea. A novel technology is evolving that will help miniaturizing the stimulation source. Vertical-Cavity Surface-Emitting Lasers (VCSELs) are available for wavelengths between 473 and 1064 and are currently developed for $1855 \mathrm{~nm}$. VCSELs can be a few micrometers in size and can be placed closed to the target structure. The challenge to place the optical source close to the neural structure is the heat development of the source. Only a fraction of the energy used by light source is converted into photons, the rest is converted to heat. Local heating constitutes a problem.

Alternate approaches include the delivery of the light via optical fibers or waveguides. While an optical fiber-based prosthesis may be suitable for a low-density prosthesis application (stimulation of 1-5 distinct sites), prostheses that encode more dense information, such as cochlear implants and visual prostheses, would be difficult to implement with 50-100 or more individually addressed optical fibers. Possible design solutions for these applications include a scanning optical source that sequentially addresses multiple stimulating sites or a high-density array of small solid-state optical sources that can simultaneously stimulate multiple neural populations. Optical fibers face another challenge, they are stiff and difficult to place along the cochlea. The fibers may break during the insertion or they damage cochlear tissue. Optical fiber bundles, which are used to irradiate neurons along one half of the basal turn, are unlikely a solution for a chronically implanted light delivery system.

In addition to the type of source used, the placement of the optical source has implications for the prosthesis design. An external source would allow for a higher power, larger battery capacity, and easy modifications to the stimulating source. However, by transmitting the optical energy transcutaneously, a significant portion of the optical power would be lost. Percutaneous links, while possible, are much less desirable due to the risk of infection. A fully implantable optical prosthesis is desirable because it eliminates the transcutaneous link except for battery charging. However, hardware upgrades are difficult with a fully implantable device. Furthermore, implanted optical sources need to be more efficient than externally mounted sources to reduce the heat generated by powering the device. It remains 
to be seen if a solid state device can be constructed with the size and power requirements to be fully implanted and to stimulate neurons.

Light-Emitting Diodes (LEDs) possess a narrow spectral line-width and a high temporal fidelity. They are an attractive light source for benchtop optogenetic applications. Again, LEDs generate substantial heat and their in vivo use requires precaution to avoid heat damage of the tissue.

At present a single channel and a three channel light delivery and stimulation system has been developed for the cat cochlea for INS. The three-channel system is a wirelessly controlled, battery-powered, wearable unit $(<200 \mathrm{~g})$ for chronic stimulation studies in large animal models (i.e. cat). Three individually controllable lasers are housed in the smaller package, which can be carried in a backpack). Individual control of each laser stimulator allows real-time control of all laser parameters, including power $(0-250 \mathrm{~mW})$, repetition rate $(0-300 \mathrm{~Hz})$, pulse width $(50 \mu \mathrm{s}-1 \mathrm{~ms})$, and wavelength $(1.85-1.87 \mu \mathrm{m})$. All data (stimulation inputs and recorded outputs) are time stamped, sorted, saved, and easily accessible from a GUI. A breakaway interface connector allows for attachment/detachment of various optical fiber-based implantable light delivery systems with up to 3 channels with $<1 \%$ variability in optical transmission. While the single channel system has been tested in a longterm study (Matic et al., 2013), the three-channel system is still under investigation.

\section{Conclusions and Future Directions}

Recent research efforts have demonstrated that optical radiation can be used to stimulate neurons. With the development of compact light sources to evoke neural responses, it has been validated that stimulation with optical radiation is spatially selective. Stimulation with optical radiation has advantages and limitations when compared with stimulation with electric current. The differences between stimulation modalities could be selectively exploited for the next generation of neural interfaces and as a neurophysiology research tool.

INS, as a tool, could advance our understanding of many research-based neuroscience questions and lead to significant findings that would otherwise not be possible with conventional stimulation paradigms. In addition, the possibility of using INS for a neural prosthesis has its appeal. Many steps are required between technological conception and maturity of an INS-based prosthesis. The steps include biological safety and compatibility and the engineering of a practicable device.

With the objective to design and build INS prostheses, it would be extremely important to understand the mechanism. It will allow optimization of the laser parameter space and will aid the long-term safety of INS. Further work to understand the effect of beam quality (e.g. focused beam vs. collimated beam) on stimulation will aid in the design of efficient research and clinical stimulators.

Most of the work, to date, has been executed in vivo, and as such it would be useful to determine any differences with INS in vitro. Many neural systems and neuron types have yet to be stimulated with infrared radiation and it is unknown if INS will work on all neurons or 
only a subset. While there are many questions yet to be answered, INS provides a unique application of biomedical optics that may foster significant advances in neuroscience.

The possibility to express channels that can activate or inhibit cells upon irradiation with visible light of different colors has opened endless opportunities to manipulate and study neural networks. Optogenetics thus enables us to study and understand the complex function of our brain. Although the mechanism and method to express light sensitive channel in neurons or cells is known in theory, challenges still exist to selectively target the cells.

The advancement of optogenetics and thermogenetics also requires the development of enabling technology. Visible light is largely scattered in tissue and requires small light sources to be placed close to the target structures. These needs for the field will nurture engineering attempts for building small and powerful light sources and the development of advanced and more efficient waveguides.

The biggest challenge for optogenetics will be the translation into the clinic. It has to be demonstrated, that expression of the optogenetics tools is safe. Furthermore, it will be important to show that effective stimulation of selected structures is possible in large volumes, different to those present in small rodents such as mice.

\section{Acknowledgments}

This project has been funded with federal funds from the National Institute on Deafness and Other Communication Disorders, R01 DC011855.

\section{Abbreviations}

$\begin{array}{ll}\text { AAV } & \text { adeno-associated viral vectors } \\ \text { ABR } & \text { auditory brainstem response } \\ \text { oABR } & \text { optically evoked auditory brainstem response } \\ \text { AP } & \text { action potential } \\ \text { BSL } & \text { bio safety level } \\ \text { Ca } & \text { calcium ion } \\ \text { CAP } & \text { compound action potential } \\ \text { ChR } & \text { channelrhodopsin } \\ \text { Cm } & \text { centimeter } \\ \text { CmAP } & \text { Compound muscle action potential } \\ \text { cw } & \text { continuous wave } \\ \boldsymbol{d B} & \text { decibel } \\ \text { DP-OCT } & \text { differential phase optical coherence tomography } \\ \boldsymbol{E} & \text { fluence rate }\end{array}$


eV

FEL

$f$

fs

HEK293 cells

HeNe

Ho:YAG

H

HR

$\mathrm{Hz}$

ICC

INS

J

LV

Nd:YAG

M

NA

m

mm

ms

nm

ns

$\mathrm{OHC}$

$\mathrm{Pa}$

$P$

$Q$

S

SPL

TEM

Ti:Sapphire

TRP

TRPV electron Volt

free electron laser

repetition rate

fempto second

Human Embryonic Kidney 293 cells

Helium-Neon

Holmium-doped yttrium aluminum garnet

radiant exposure

halorhodopsin

Hertz, 1/s

central nucleus of the inferior colliculus

infrared neural stimulation

Joule

lentiviral vectors

neodymium-doped yttrium aluminum garnet

Mole

numerical aperture

musculus

millimeter

millisecond

nanometer

nanosecond

outer hair cell

Pascal

power

radiant energy

seconds

sound pressure level (reference pressure is $20 \mu \mathrm{Pa}$ )

transmission electron microscope

Titanium-sapphire

transient receptor potential

transient receptor potential vanilloid 


$\begin{array}{ll}\mathbf{W} & \text { Watt } \\ \text { Yb:glass } & \text { Ytterbium-doped glasses } \\ \lambda & \text { wavelength } \\ \tau_{\mathbf{p}} & \text { pulse length } \\ \mu \mathbf{m} & \text { micrometer } \\ { }^{\circ} \mathbf{C} & \text { degree Celsius } \\ \varphi & \text { fluence rate }\end{array}$

\section{References}

Acker L, Huang B, Hancock KE, Hauswirth W, Boyden ES, Brown MC, Lee DJ. Channelrhodopsin-2 gene transfection of central auditory neurons: Toward an optical prosthesis. Abstr Assoc Res Otolaryngol. 2011; 34:484.

Adamantidis AR, Zhang F, Aravanis AM, Deisseroth K, de Lecea L. Neural substrates of awakening probed with optogenetic control of hypocretin neurons. Nature. 2007; 450:420-4. [PubMed: 17943086]

Akerboom J, Carreras Calderon N, Tian L, Wabnig S, Prigge M, Tolo J, Gordus A, Orger MB, Severi KE, Macklin JJ, Patel R, Pulver SR, Wardill TJ, Fischer E, Schuler C, Chen TW, Sarkisyan KS, Marvin JS, Bargmann CI, Kim DS, Kugler S, Lagnado L, Hegemann P, Gottschalk A, Schreiter ER, Looger LL. Genetically encoded calcium indicators for multi-color neural activity imaging and combination with optogenetics. Front Mol Neurosci. 2013; 6:2. [PubMed: 23459413]

Albert ES, Bec JM, Desmadryl G, Chekroud K, Travo C, Gaboyard S, Bardin F, Marc I, Dumas M, Lenaers G, Hamel C, Muller A, Chabbert C. TRPV4 channels mediate the infrared laser-evoked response in sensory neurons. Journal of neurophysiology. 2012; 107:3227-34. [PubMed: 22442563]

Aravanis AM, Wang LP, Zhang F, Meltzer LA, Mogri MZ, Schneider MB, Deisseroth K. An optical neural interface: in vivo control of rodent motor cortex with integrated fiberoptic and optogenetic technology. J Neural Eng. 2007; 4:S143-56. [PubMed: 17873414]

Arenkiel BR, Peca J, Davison IG, Feliciano C, Deisseroth K, Augustine GJ, Ehlers MD, Feng G. In vivo light-induced activation of neural circuitry in transgenic mice expressing channelrhodopsin-2. Neuron. 2007; 54:205-18. [PubMed: 17442243]

Arsonval AD. La fibre musculaire est directement excitable par la lumiere. CR Soc Biol. 1891; 43:318-320.

Arvanitaki, A.; Chalazonitis, N. Excitatiory and inhibitory processes initiated by light and infra-red radiations in single identifiable nerve cells. In: Florey, E., editor. Nervous Inhibition. Pergamon Press; New York: 1961.

Bagis S, Comelekoglu U, Sahin G, Buyukakilli B, Erdogan C, Kanik A. Acute electrophysiologic effect of pulsed gallium-arsenide low energy laser irradiation on configuration of compound nerve action potential and nerve excitability. Lasers in surgery and medicine. 2002; 30:376-80. [PubMed: 12116331]

Balaban CD, Zhou J, Li H. Type 1 vanilloid receptor expression by mammalian inner ear ganglion cells. Hear Res. 2003; 175:165-170. [PubMed: 12527134]

Balaban P, Esenaliev R, Karu T, Kutomkina V, Letokhov V, Oraevsky A, Ovcharenko N. He-Ne laser irridation of single identified neurons. Laser in Surgery and Medicine. 1992; 12:329-337.

Baumhoff, P.; Schultz, M.; Kallweit, N.; Krueger, A.; Ripken, T.; Lenarz, T.; Kral, A. Midbrain activity evoked by pulsed laser light. 2013 Conference on Implantable Auditory Prostheses; 2013. p. 135

Bell AG. The Photophone. Science. 1880; 1:130-4. 
Berndt A, Yizhar O, Gunaydin LA, Hegemann P, Deisseroth K. Bi-stable neural state switches. Nat Neurosci. 2009; 12:229-34. [PubMed: 19079251]

Berndt A, Schoenenberger P, Mattis J, Tye KM, Deisseroth K, Hegemann P, Oertner TG. Highefficiency channelrhodopsins for fast neuronal stimulation at low light levels. Proc Natl Acad Sci U S A. 2011; 108:7595-600. [PubMed: 21504945]

Bernstein JG, Garrity PA, Boyden ES. Optogenetics and thermogenetics: technologies for controlling the activity of targeted cells within intact neural circuits. Current opinion in neurobiology. 2012; 22:61-71. [PubMed: 22119320]

Booth J, von MA, Stampfli R. The photochemical action of ultra-violet light on isolated single nerve fibres. Helvetica physiologica et pharmacologica acta. 1950; 8:110-27. [PubMed: 15435963]

Boutros PJ, Ahn J, Fridman GY, Dai C, Lasker D, DCDS. Vestibulo-Ocular Reflex Eye Movement Responses to Infra-Red Laser Stimulation of the Mammalian Labyrinth. Abstr Assoc Res Otolaryngol. 2013; 36:255.

Boyden ES, Zhang F, Bamberg E, Nagel G, Deisseroth K. Millisecond-timescale, genetically targeted optical control of neural activity. Nat Neurosci. 2005; 8:1263-8. [PubMed: 16116447]

Callaway EM, Yuste R. Stimulating neurons with light. Current opinion in neurobiology. 2002; 12:587-92. [PubMed: 12367640]

Caterina MJ, Schumacher MA, Tominaga M, Rosen TA, Levine JD, Julius D. The capsaicin receptor: a heat-activated ion channel in the pain pathway. Nature. 1997; 389:816-824. [PubMed: 9349813]

Cayce JM, Friedman RM, Jansen ED, Mahavaden-Jansen A, Roe AW. Pulsed infrared light alters neural activity in rat somatosensory cortex in vivo. Neuroimage. 2011; 57:155-66. [PubMed: 21513806]

Cayce JM, Friedman RM, Chen G, Jansen ED, Mahadevan-Jansen A, Roe AW. Infrared neural stimulation of the primary visual cortex in non-human primates. Neuroimage. 2013

Chaudhury D, Walsh JJ, Friedman AK, Juarez B, Ku SM, Koo JW, Ferguson D, Tsai HC, Pomeranz L, Christoffel DJ, Nectow AR, Ekstrand M, Domingos A, Mazei-Robison MS, Mouzon E, Lobo MK, Neve RL, Friedman JM, Russo SJ, Deisseroth K, Nestler EJ, Han MH. Rapid regulation of depression-related behaviours by control of midbrain dopamine neurons. Nature. 2013; 493:532-6. [PubMed: 23235832]

Chen BT, Yau HJ, Hatch C, Kusumoto-Yoshida I, Cho SL, Hopf FW, Bonci A. Rescuing cocaineinduced prefrontal cortex hypoactivity prevents compulsive cocaine seeking. Nature. 2013; 496:359-62. [PubMed: 23552889]

Chow BY, Han X, Dobry AS, Qian X, Chuong AS, Li M, Henninger MA, Belfort GM, Lin Y, Monahan PE, Boyden ES. High-performance genetically targetable optical neural silencing by light-driven proton pumps. Nature. 2010; 463:98-102. [PubMed: 20054397]

Dalva MB, Katz LC. Rearrangements of synaptic connections in visual cortex revealed by laser photostimulation. Science. 1994; 265:255-8. [PubMed: 7912852]

Darrow K, Slama M, Kempfle J, Boyden ES, Polley D, Brown MC, Lee DJ. A comparison of electrical and optical activation of midbrain and cortical pathways in mice expressing channelrhodopsin-2 in the cochlear nucleus. Abstr Assoc Res Otolaryngol. 2013a; 36:265.

Darrow K, Slama M, Kempfle J, Boyden ES, Polley D, Brown MC, Lee DJ. Optogenetic control of central auditory neurons. Abstr Assoc Res Otolaryngol. 2013b; 36:695.

Dittami GM, Rajguru SM, Lasher RA, Hitchcock RW, Rabbitt RD. Intracellular calcium transients evoked by pulsed infrared radiation in neonatal cardiomyocytes. J Physiol. 2011; 589:1295-306. [PubMed: 21242257]

Douglass AD, Kraves S, Deisseroth K, Schier AF, Engert F. Escape behavior elicited by single, channelrhodopsin-2-evoked spikes in zebrafish somatosensory neurons. Curr Biol. 2008; 18:11337. [PubMed: 18682213]

Duke AR, Lu H, Jenkins MW, Chiel HJ, Jansen ED. Spatial and temporal variability in response to hybrid electro-optical stimulation. J Neural Eng. 2012; 9:036003. [PubMed: 22505590]

Duke AR, Cayce JM, Malphrus JD, Konrad P, Mahadevan-Jansen A, Jansen ED. Combined optical and electrical stimulation of neural tissue in vivo. J Biomed Opt Lett. 2009; 14:060501. 
Duschl A, Lanyi JK, Zimanyi L. Properties and photochemistry of a halorhodopsin from the haloalkalophile, Natronobacterium pharaonis. J Biol Chem. 1990; 265:1261-7. [PubMed: 2104838]

Eder M, Zieglgansberger W, Dodt HU. Shining light on neurons--elucidation of neuronal functions by photostimulation. Reviews in the neurosciences. 2004; 15:167-83. [PubMed: 15357140]

Falk M, Ford TA. Infrared spectrum and structure of liquid water. Can J Chem. 1966; 44:1699-1707.

Farber IC, Grinvald A. Identification of presynaptic neurons by laser photostimulation. Science. 1983; 222:1025-7. [PubMed: 6648515]

Favero M, Castro-Alamancos MA. Synaptic cooperativity regulates persistent network activity in neocortex. The Journal of neuroscience : the official journal of the Society for Neuroscience. 2013; 33:3151-63. [PubMed: 23407969]

Feng HJ, Kao C, Gallagher MJ, Jansen ED, Mahadevan-Jansen A, Konrad PE, Macdonald RL. Alteration of GABAergic neurotransmission by pulsed infrared laser stimulation. Journal of neuroscience methods. 2010; 192:110-4. [PubMed: 20654645]

Fork R. Laser stimulation of nerve cells in aplysia. Science. 1971:907-908. [PubMed: 5541653]

Fried, NM.; Lagoda, GA.; Scott, NJ.; Su, LM.; Burnett, AL. Laser stimulation of the cavernous nerves in the rat prostate, in vivo: optimization of wavelength, pulse energy, and pulse repetition rate. Conference proceedings : Annual International Conference of the IEEE Engineering in Medicine and Biology Society. IEEE Engineering in Medicine and Biology Society Conference; 2008; 2008a. p. 2777-80.

Fried NM, Lagoda GA, Scott NJ, Su LM, Burnett AL. Noncontact stimulation of the cavernous nerves in the rat prostate using a tunable-wavelength thulium fiber laser. Journal of endourology / Endourological Society. 2008b; 22:409-13. [PubMed: 18257657]

Govorunova EG, Spudich EN, Lane CE, Sineshchekov OA, Spudich JL. New channelrhodopsin with a red-shifted spectrum and rapid kinetics from Mesostigma viride. mBio. 2011; 2:e00115-11. [PubMed: 21693637]

Goyal V, Rajguru S, Matic AI, Stock SR, Richter CP. Acute damage threshold for infrared neural stimulation of the cochlea: functional and histological evaluation. Anat Rec (Hoboken). 2012; 295:1987-99. [PubMed: 23044730]

Gradinaru V, Mogri M, Thompson KR, Henderson JM, Deisseroth K. Optical deconstruction of parkinsonian neural circuitry. Science. 2009; 324:354-9. [PubMed: 19299587]

Gradinaru V, Thompson KR, Zhang F, Mogri M, Kay K, Schneider MB, Deisseroth K. Targeting and readout strategies for fast optical neural control in vitro and in vivo. J Neurosci. 2007; 27:14231-8. [PubMed: 18160630]

Gradinaru V, Zhang F, Ramakrishnan C, Mattis J, Prakash R, Diester I, Goshen I, Thompson KR, Deisseroth K. Molecular and cellular approaches for diversifying and extending optogenetics. Cell. 2010; 141:154-65. [PubMed: 20303157]

Greffrath W, Nemenov MI, Schwarz S, Baumgartner U, Vogel H, Arendt-Nielsen L, Treede RD. Inward currents in primary nociceptive neurons of the rat and pain sensations in humans elicited by infrared diode laser pulses. Pain. 2002; 99:145-55. [PubMed: 12237192]

Grill WM, Norman SE, Bellamkonda RV. Implanted neural interfaces: biochallenges and engineered solutions. Annu Rev Biomed Eng. 2009; 11:1-24. [PubMed: 19400710]

Grossman N, Nikolic K, Toumazou C, Degenaar P. Modeling study of the light stimulation of a neuron cell with channelrhodopsin-2 mutants. IEEE transactions on bio-medical engineering. 2011; 58:1742-51. [PubMed: 21324771]

Grossman N, Simiaki V, Martinet C, Toumazou C, Schultz SR, Nikolic K. The spatial pattern of light determines the kinetics and modulates backpropagation of optogenetic action potentials. J Comput Neurosci. 2013; 34:477-88. [PubMed: 23179855]

Güler AD, Lee H, Iida T, Shimizu I, Tominaga M, Caterina M. Heat-evoked activation of the ion channel, TRPV4. J Neurosci. 2002; 22:6408-6414. [PubMed: 12151520]

Gunaydin LA, Yizhar O, Berndt A, Sohal VS, Deisseroth K, Hegemann P. Ultrafast optogenetic control. Nat Neurosci. 2010; 13:387-92. [PubMed: 20081849] 
Hägglund M, Borgius L, Dougherty KJ, Kiehn O. Activation of groups of excitatory neurons in the mammalian spinal cord or hindbrain evokes locomotion. Nat Neurosci. 2010; 13:246-52. [PubMed: 20081850]

Hale GM, Querry MR. Optical constants of water in the 200-nm to 200- $\mu$ m wavelength range. Appl Opt. 1973; 12:555-563. [PubMed: 20125343]

Han X, Qian X, Bernstein JG, Zhou HH, Franzesi GT, Stern P, Bronson RT, Graybiel AM, Desimone R, Boyden ES. Millisecond-timescale optical control of neural dynamics in the nonhuman primate brain. Neuron. 2009; 62:191-8. [PubMed: 19409264]

Harris DM, Bierer SM, Wells JD, Phillips JO. Optical nerve stimulation for a vestibular prosthesis. Proc SPIE. 2009; 7180:71800R.

Harteneck C, Plant TD, Schulz Gun. From worm to man: three subfamilies of TRP channels. Trends Neurosci. 2000; 23:159-166. [PubMed: 10717675]

Hegemann P, Moglich A. Channelrhodopsin engineering and exploration of new optogenetic tools. Nature methods. 2011; 8:39-42. [PubMed: 21191371]

Hegemann P, Ehlenbeck S, Gradmann D. Multiple photocycles of channelrhodopsin. Biophysical Journal. 2005; 89:3911-8. [PubMed: 16169986]

Hernandez VH, Hoch G, Reuter K, Jing Z, Bartels M, Vogt G, Garnham CW, Augustine GJ, Kügler S, Salditt T, Strenzke N, Moser T. Optogenetic stimulation of the auditory nerve:Towards an optical cochlear prosthetic. Abstr Assoc Res Otolaryngol. 2013; 36:694.

Hernandez VH, Gehrt A, Reuter K, Jing Z, Jeschke M, Mendoza Schulz A, Hoch G, Bartels M, Vogt G, Garnham CW, Yawo H, Fukazawa Y, Augustine GJ, Bamberg E, Kugler S, Salditt T, de Hoz L, Strenzke N, Moser T. Optogenetic stimulation of the auditory pathway. J Clin Invest. 2014; 124:1114-29. [PubMed: 24509078]

Hira R, Ohkubo F, Tanaka YR, Masamizu Y, Augustine GJ, Kasai H, Matsuzaki M. In vivo optogenetic tracing of functional corticocortical connections between motor forelimb areas. Front Neural Circuits. 2013; 7:55. [PubMed: 23554588]

Hirase H, Nikolenko V, Goldberg JH, Yuste R. Multiphoton stimulation of neurons. Journal of neurobiology. 2002; 51:237-47. [PubMed: 11984845]

Holstein GR, Martinelli GP, Boyle R, Rabbitt RD, Highstein SM. Ultrastructural observations of efferent terminals in the crista Ampullaris of the toadfish, opsanus tau. Exp Brain Res. 2004a; 155:265-73. [PubMed: 14689144]

Holstein GR, Rabbitt RD, Martinelli GP, Friedrich VL Jr, Boyle RD, Highstein SM. Convergence of excitatory and inhibitory hair cell transmitters shapes vestibular afferent responses. Proc Natl Acad Sci U S A. 2004b; 101:15766-71. [PubMed: 15505229]

Imayoshi I, Tabuchi S, Hirano K, Sakamoto M, Kitano S, Miyachi H, Yamanaka A, Kageyama R. Light-induced silencing of neural activity in Rosa26 knock-in mice conditionally expressing the microbial halorhodopsin eNpHR2.0. Neurosci Res. 2013; 75:53-8. [PubMed: 22465523]

Ishizuka T, Kakuda M, Araki R, Yawo H. Kinetic evaluation of photosensitivity in genetically engineered neurons expressing green algae light-gated channels. Neurosci Res. 2006; 54:85-94. [PubMed: 16298005]

Izzo AD, Richter CP, Jansen ED, Walsh JT. Laser stimulation of the auditory nerve. Laser Surg Med. 2006; 38:745-753.

Izzo AD, Suh E, Pathria J, Walsh JT, Whitlon DS, Richter CP. Selectivity of neural stimulation in the auditory system: a comparison of optic and electric stimuli. Journal of biomedical optics. 2007a; 12:021008. [PubMed: 17477715]

Izzo AD, Joseph T, Walsh J, Jansen ED, Bendett M, Webb J, Ralph H, Richter CP. Optical parameter variability in laser nerve stimulation: a study of pulse duration, repetition rate, and wavelength. IEEE Trans Biomed Eng. 2007b; 54:1108-1114. [PubMed: 17554829]

Izzo AD, Walsh JT, Ralph H, Webb J, Bendett M, Wells J, Richter C-P. Laser stimulation of auditory neurons at shorter pulse durations and penetration depths. Biophys J. 2008:94.

Jacques SL. Laser-tissue interactions. Photochemical, photothermal, and photomechanical. The Surgical clinics of North America. 1992; 72:531-58. [PubMed: 1589829]

Jacques SL. Optical properties of biological tissues: a review. Phys Med Biol. 2013; 58:R37-61. [PubMed: 23666068] 
Jenkins MW, Duke AR, Gu S, Chiel HJ, Fujioka H, Watanabe M, Jansen ED, Rollins AM. Optical pacing of the embryonic heart. Nat Photonics. 2010; 4:623-626. [PubMed: 21423854]

Jennings JH, Sparta DR, Stamatakis AM, Ung RL, Pleil KE, Kash TL, Stuber GD. Distinct extended amygdala circuits for divergent motivational states. Nature. 2013; 496:224-8. [PubMed: 23515155]

Jia Z, Valiunas V, Lu Z, Bien H, Liu H, Wang HZ, Rosati B, Brink PR, Cohen IS, Entcheva E. Stimulating cardiac muscle by light: cardiac optogenetics by cell delivery. Circ Arrhythm Electrophysiol. 2011; 4:753-60. [PubMed: 21828312]

Kadakia S, Young H, Richter C-P. Masking of Infrared Neural Stimulation (INS) in hearing and deaf guinea pigs. Proc of SPIE 8565-213. 2013:1-6.

Kao JPY. Caged Molecules: Principles and practical considerations. Curr Protoc Neurosci. 2006; 37(Unit 6.20)

Katz EJ, Ilev IK, Krauthamer V, Kim do H, Weinreich D. Excitation of primary afferent neurons by near-infrared light in vitro. Neuroreport. 2010; 21:662-6. [PubMed: 20495496]

Katz LC, Dalva MB. Scanning laser photostimulation: a new approach for analyzing brain circuits. Journal of neuroscience methods. 1994; 54:205-18. [PubMed: 7869753]

Kianianmomeni A, Stehfest K, Nematollahi G, Hegemann P, Hallmann A. Channelrhodopsins of Volvox carteri are photochromic proteins that are specifically expressed in somatic cells under control of light, temperature, and the sex inducer. Plant physiology. 2009; 151:347-66. [PubMed: 19641026]

Kleinlogel S, Feldbauer K, Dempski RE, Fotis H, Wood PG, Bamann C, Bamberg E. Ultra lightsensitive and fast neuronal activation with the $\mathrm{Ca}(2)+$-permeable channelrhodopsin CatCh. Nat Neurosci. 2011; 14:513-8. [PubMed: 21399632]

Kokaia M, Sorensen AT. The treatment of neurological diseases under a new light: the importance of optogenetics. Drugs Today (Barc). 2011; 47:53-62. [PubMed: 21373649]

Krook-Magnuson E, Armstrong C, Oijala M, Soltesz I. On-demand optogenetic control of spontaneous seizures in temporal lobe epilepsy. Nat Commun. 2013; 4:1376. [PubMed: 23340416]

Lee DJ, Hancock KE, Mukerji S, Brown MC. Optical stimulation of the central auditory system. Abstr Assoc Res Otolaryngol. 2009; 32:314.

Lee DJ, Hancock KE, Mukerji S, Verma R, Brown MC. Infrared neural stimulation of the cochelar nucleus. Abstr Assoc Res Otolaryngol. 2011; 34:539.

Li X, Gutierrez DV, Hanson MG, Han J, Mark MD, Chiel H, Hegemann P, Landmesser LT, Herlitze S. Fast noninvasive activation and inhibition of neural and network activity by vertebrate rhodopsin and green algae channelrhodopsin. Proc Natl Acad Sci U S A. 2005; 102:17816-21. [PubMed: 16306259]

Liljemalm R, Nyberg T, von Holst H. Heating during infrared neural stimulation. Lasers in surgery and medicine. 2013

Lin JY, Lin MZ, Steinbach P, Tsien RY. Characterization of engineered channelrhodopsin variants with improved properties and kinetics. Biophys J. 2009; 96:1803-14. [PubMed: 19254539]

Lin JY, Knutsen PM, Muller A, Kleinfeld D, Tsien RY. ReaChR: a red- shifted variant of channelrhodopsin enables deep transcranial optogenetic excitation. Nat Neurosci. 2013; 16:1499508. [PubMed: 23995068]

Littlefield P, Izzo AD, Mundi J, Joseph T, Walsh J, Jansen ED, Bendett M, Webb J, Ralph H, Richter $\mathrm{CP}$. Characterization of single auditory nerve fibers in response to laser stimulation. Proc SPIE. 2008; 6854:68540F.

Liu Q, Jorgensen E, Holman H, Frerck M, Rabbitt RD. Miniature post synaptic currents are entrained by infrared pulses. Abstr Assoc Res Otolaryngol. 2013:464.

Liu X, Ramirez S, Pang PT, Puryear CB, Govindarajan A, Deisseroth K, Tonegawa S. Optogenetic stimulation of a hippocampal engram activates fear memory recall. Nature. 2012; 484:381-5. [PubMed: 22441246]

LoPachin RM, Stys PK. Elemental composition and water content of rat optic nerve myelinated axons and glial cells: effects of in vitro anoxia and reoxygenation. J Neurosci. 1995; 15:6735-6746. [PubMed: 7472432] 
Lumbreras V, Finale M, Bas E, Gupta C, Rajguru S. Pulsed infrared-evoked intracellular calcium transients in cultured neonatal spiral ganglion neurons. Abstr Assoc Res Otolaryngol. 2013; 36:341.

Mahadevan-Jansen, A.; Cayce, JM.; Friedman, R.; Roe, AW.; Konrad, PE.; Hillman, E.; Jansen, E. Imaging optically induced neural activity in the brain. Conference proceedings : Annual International Conference of the IEEE Engineering in Medicine and Biology Society. IEEE Engineering in Medicine and Biology Society Conference; 2010; 2010. p. 3379-81.

Man D, Wang W, Sabehi G, Aravind L, Post AF, Massana R, Spudich EN, Spudich JL, Beja O. Diversification and spectral tuning in marine proteorhodopsins. Embo J. 2003; 22:1725-31. [PubMed: 12682005]

Matic AI, Walsh JT Jr, Richter CP. Spatial extent of cochlear infrared neural stimulation determined by tone-on-light masking. Journal of biomedical optics. 2011; 16:118002. [PubMed: 22112140]

Matic AI, Robinson AM, Young HK, Badofsky B, Rajguru SM, Stock S, Richter CP. Behavioral and electrophysiological responses evoked by chronic infrared neural stimulation of the cochlea. PLoS One. 2013; 8:e58189. [PubMed: 23505466]

Matsui K. Mind control with optogenetic mice: exploring the causal relationships between brain activity and the mind. Brain Nerve. 2013; 65:609-21. [PubMed: 23735523]

Matsuno-Yagi A, Mukohata Y. Two possible roles of bacteriorhodopsin; a comparative study of strains of Halobacterium halobium differing in pigmentation. Biochem Biophys Res Commun. 1977; 78:237-43. [PubMed: 20882]

McCaughey RG, Chlebicki C, Wong BJ. Novel wavelengths for laser nerve stimulation. Lasers in surgery and medicine. 2010; 42:69-75. [PubMed: 19802885]

Montell C. The TRP superfamily of cation channels. Science STKE. 2005:re3.

Moser T, Hernandez VH, Hoch G, Reuter K, Jing Z, Bartels M, Vogt G, Garnham CW, Augustine GJ, Kügler S, Salditt T, Strenzke N. Optogenetic Stimulation of the Auditory Nerve. Abstr Assoc Res Otolaryngol. 2013; 36:268.

Nagel G, Brauner M, Liewald JF, Adeishvili N, Bamberg E, Gottschalk A. Light activation of channelrhodopsin-2 in excitable cells of Caenorhabditis elegans triggers rapid behavioral responses. Curr Biol. 2005; 15:2279-84. [PubMed: 16360690]

Nagel G, Ollig D, Fuhrmann M, Kateriya S, Musti AM, Bamberg E, Hegemann P. Channelrhodopsin-1: a light-gated proton channel in green algae. Science. 2002; 296:2395-8. [PubMed: 12089443]

Nagel G, Szellas T, Huhn W, Kateriya S, Adeishvili N, Berthold P, Ollig D, Hegemann P, Bamberg E. Channelrhodopsin-2, a directly light-gated cation-selective membrane channel. Proc Natl Acad Sci U S A. 2003; 100:13940-5. [PubMed: 14615590]

Nathan RD, Pooler JP, DeHaan RL. Ultraviolet-induced alterations of beat rate and electrical properties of embryonic chick heart cell aggregates. J Gen Physiol. 1976; 67:27-44. [PubMed: 942742]

Nelson A, Schneider DM, Takatoh J, Sakurai K, Wang F, Mooney R. A circuit for motor cortical modulation of auditory cortical activity. The Journal of neuroscience : the official journal of the Society for Neuroscience. 2013; 33:14342-53. [PubMed: 24005287]

Niemz, MH. Laser Tissue interactions: fundamentals and application. 2. Springer; New York: 2004.

Norton BJ, Bowler MA, Wells JD, Keller MD. Analytical approaches for determining heat distributions and thermal criteria for infrared neural stimulation. Journal of biomedical optics. 2013; 18:98001.

Oesterhelt D, Stoeckenius W. Rhodopsin-like protein from the purple membrane of Halobacterium halobium. Nat New Biol. 1971; 233:149-52. [PubMed: 4940442]

Oesterhelt D, Krippahl G. Light inhibition of respiration in Halobacterium halobium. FEBS Lett. 1973; 36:72-6. [PubMed: 4747602]

Oesterhelt D, Meentzen M, Schuhmann L. Reversible dissociation of the purple complex in bacteriorhodopsin and identification of 13-cis and all-trans-retinal as its chromophores. Eur J Biochem. 1973; 40:453-63. [PubMed: 4781385]

Olcese U, Iurilli G, Medini P. Cellular and synaptic architecture of multisensory integration in the mouse neocortex. Neuron. 2013; 79:579-93. [PubMed: 23850594] 
Olson JE, Schimmerling W, Tobias CA. Laser action spectrum of reduced excitability in nerve cells. Brain research. 1981a; 204:436-40. [PubMed: 6257329]

Olson JE, Schimmerling W, Gundy GC, Tobias CA. Laser microirradiation of cerebellar neurons in culture. Electrophysiological and morphological effects. Cell biophysics. 1981b; 3:349-71. [PubMed: 6175420]

Orchardson R, Peacock JM, Witters CJ. Effect of pulsed Nd:YAG laser radiation on action potential conduction in isolated mammalian spinal nerves. Laser Surg Med. 1997; 21:142-148.

Pisauro MA, Dhruv NT, Carandini M, Benucci A. Fast hemodynamic responses in the visual cortex of the awake mouse. J Neurosci. 2013; 33:18343-51. [PubMed: 24227743]

Rabbitt RD, Boyle R, Highstein SM. Mechanical indentation of the vestibular labyrinth and its relationship to head rotation in the toadfish, Opsanus tau. J Neurophysiol. 1995; 73:2237-60. [PubMed: 7666136]

Rajguru, SM.; Rabbitt, RR.; Matic, AI.; Highstein, SM.; Richter, CP. Selective activation of vestibular hair cells by infrared light. Biophysical Society 54th Annual Meeting; San Fransisco, CA: Biophysical Society; 2010a.

Rajguru, SM.; Rabbitt, RR.; Matic, AI.; Highstein, SM.; Richter, CP. Inhibitory and Excitatory Vestibular Afferent Responses Induced By Infrared Light Stimulation of Hair Cells. 33rd Midwinter Meeting; Anaheim, CA: Association for Research in Otolaryngology; 2010b.

Rajguru SM, Matic AI, Robinson AM, Fishman AJ, Moreno LE, Bradley A, Vujanovic I, Breen J, Wells JD, Bendett M, Richter CP. Optical cochlear implants: evaluation of surgical approach and laser parameters in cats. Hearing research. 2010c; 269:102-11. [PubMed: 20603207]

Ramirez S, Liu X, Lin PA, Suh J, Pignatelli M, Redondo RL, Ryan TJ, Tonegawa S. Creating a false memory in the hippocampus. Science. 2013; 341:387-91. [PubMed: 23888038]

Rhee AY, Li G, Wells J, Kao YPY. Photostimulation of sensory neurons of the rat vagus nerve. SPIE. 2008; 6854:68540E1.

Richter CP, Bayon R, Izzo AD, Otting M, Suh E, Goyal S, Hotaling J, Walsh JT Jr. Optical stimulation of auditory neurons: effects of acute and chronic deafening. Hear Res. 2008; 242:42-51. [PubMed: 18321670]

Richter CP, Rajguru SM, Matic AI, Moreno EL, Fishman AJ, Robinson AM, Suh E, Walsh JT. Spread of cochlear excitation during stimulation with pulsed infrared radiation: inferior colliculus measurements. J Neural Eng. 2011; 8:056006. [PubMed: 21828906]

Rosenberg HF, Gunner JT. Sodium, potassium and water contents of various components (intact, desheathed nerve, and epineurium) of fresh (untreated) medullated (sciatic) nerve of R. ridibunda (and some comparative data on cat sciatic). Pflügers Arch. 1959; 269:270-273.

Ruiz O, Lustig BR, Nassi JJ, Cetin AH, Reynolds JH, Albright TD, Callaway EM, Stoner GR, Roe AW. Optogenetics through windows on the brain in the nonhuman primate. Journal of neurophysiology. 2013

Schoenenberger P, Gerosa D, Oertner TG. Temporal control of immediate early gene induction by light. PLoS One. 2009; 4:e8185. [PubMed: 19997631]

Schultz M, Baumhoff P, Teudt IU, Maier H, Kruger A, Lenarz T, Kral A. Pulsed wavelengthdependent laser stimulation of the inner ear. Biomed Tech (Berl). 2012a; 57(Suppl 1)

Schultz M, Baumhoff P, Maier H, Teudt IU, Kruger A, Lenarz T, Kral A. Nanosecond laser pulse stimulation of the inner ear-a wavelength study. Biomed Opt Express. 2012b; 3:3332-45. [PubMed: 23243582]

Shapiro MG, Homma K, Villarreal S, Richter CP, Bezanilla F. Infrared light excites cells by changing their electrical capacitance. Nat Commun. 2012; 3:736. [PubMed: 22415827]

Smith NI, Kumamoto Y, Iwanaga S, Ando J, Fujita K, Kawata S. A femtosecond laser pacemaker for heart muscle cells. Opt Express. 2008; 16:8604-16. [PubMed: 18545573]

Sohal VS, Zhang F, Yizhar O, Deisseroth K. Parvalbumin neurons and gamma rhythms enhance cortical circuit performance. Nature. 2009; 459:698-702. [PubMed: 19396159]

Stroh A, Adelsberger H, Groh A, Ruhlmann C, Fischer S, Schierloh A, Deisseroth K, Konnerth A. Making waves: initiation and propagation of corticothalamic Ca2+ waves in vivo. Neuron. 2013; 77:1136-50. [PubMed: 23522048] 
Suh E, Matic AI, Otting M, Walsh JT Jr, Richter CP. Optical stimulation in mice which lack the TRPV1 channel. Proc of SPIE. 2009; 7180:71800S 1-5.

Takumida M, Kubo N, Ohtani M, Suzuka Y, Anniko M. Transient receptor potential channels in the inner ear: Presence of transient receptor potential channel subfamily 1 and 4 in the guinea pig inner ear. Acta Otolaryngol. 2005; 125:929-934. [PubMed: 16193584]

Tamura K, Ohashi Y, Tsubota T, Takeuchi D, Hirabayashi T, Yaguchi M, Matsuyama M, Sekine T, Miyashita Y. A glass-coated tungsten microelectrode enclosing optical fibers for optogenetic exploration in primate deep brain structures. Journal of neuroscience methods. 2012; 211:49-57. [PubMed: 22971353]

Teudt I, Nevel A, Izzo AD, Walsh JT, Richter CP. Optical stimulation of the facial nerve: a new monitoring technique? Laryngoscope. 2007; 117:1641-1647. [PubMed: 17607145]

Teudt IU, Maier H, Richter CP, Kral A. Acoustic events and "optophonic" cochlear responses induced by pulsed near-infrared laser. IEEE transactions on bio-medical engineering. 2011; 58:1648-55. [PubMed: 21278011]

Thompson A, Wade S, Pawsey N, Stoddart P. Infrared Neural Stimulation: Influence of stimulation site spacing and repetition rates on heating. IEEE transactions on bio-medical engineering. 2013a

Thompson AC, Wade SA, Brown WG, Stoddart PR. Modeling of light absorption in tissue during infrared neural stimulation. Journal of biomedical optics. 2012; 17:075002. [PubMed: 22894474]

Thompson AC, Wade SA, Cadusch PJ, Brown WG, Stoddart PR. Modeling of the temporal effects of heating during infrared neural stimulation. Journal of biomedical optics. 2013b; 18:035004. [PubMed: 23471490]

Thyagarajan S, van Wyk M, Lehmann K, Lowel S, Feng G, Wassle H. Visual function in mice with photoreceptor degeneration and transgenic expression of channelrhodopsin 2 in ganglion cells. The Journal of neuroscience : the official journal of the Society for Neuroscience. 2010; 30:8745-58. [PubMed: 20592196]

Tozburun S, Lagoda GA, Burnett AL, Fried NM. Subsurface near-infrared laser stimulation of the periprostatic cavernous nerves. J Biophotonics. 2012; 5:793-800. [PubMed: 22345079]

Tozburun S, Cilip CM, Lagoda GA, Burnett AL, Fried NM. Continuous-wave infrared optical nerve stimulation for potential diagnostic applications. Journal of biomedical optics. 2010; 15:055012. [PubMed: 21054094]

Tozburun S, Stahl CD, Hutchens TC, Lagoda GA, Burnett AL, Fried NM. Continuous-wave Infrared Subsurface Optical Stimulation of the Rat Prostate Cavernous Nerves Using a 1490-nm Diode Laser. Urology. 2013

Tsubota T, Ohashi Y, Tamura K, Sato A, Miyashita Y. Optogenetic manipulation of cerebellar Purkinje cell activity in vivo. PLoS One. 2011; 6:e22400. [PubMed: 21850224]

Tsunoda SP, Ewers D, Gazzarrini S, Moroni A, Gradmann D, Hegemann P. H+-pumping rhodopsin from the marine alga Acetabularia. Biophys J. 2006; 91:1471-9. [PubMed: 16731558]

Tuchin, V. Tissue optics : light scattering methods and instruments for medical diagnosis. SPIE Press; Bellingham, Wash: 2000.

Tye KM, Deisseroth K. Optogenetic investigation of neural circuits underlying brain disease in animal models. Nature reviews Neuroscience. 2012; 13:251-66.

Uzdensky AB, Savransky VV. Single neuron response to pulse-periodic laser microirradiation. Action spectra and two-photon effect. J Photochem Photobiol B: Biol. 1997; 39:224-228.

Vaiceliunaite A, Erisken S, Franzen F, Katzner S, Busse L. Spatial integration in mouse primary visual cortex. J Neurophysiol. 2013; 110:964-72. [PubMed: 23719206]

Verma RU, Guex AA, Hancock KE, Durakovic N, McKay CM, Slama MC, Brown MC, Lee DJ. Auditory responses to electric and infrared neural stimulation of the rat cochlear nucleus. Hearing research. 2014; 310C:69-75. [PubMed: 24508368]

Wang H, Sugiyama Y, Hikima T, Sugano E, Tomita H, Takahashi T, Ishizuka T, Yawo H. Molecular determinants differentiating photocurrent properties of two channelrhodopsins from chlamydomonas. J Biol Chem. 2009; 284:5685-96. [PubMed: 19103605]

Wang H, Peca J, Matsuzaki M, Matsuzaki K, Noguchi J, Qiu L, Wang D, Zhang F, Boyden E, Deisseroth K, Kasai H, Hall WC, Feng G, Augustine GJ. High-speed mapping of synaptic 
connectivity using photostimulation in Channelrhodopsin-2 transgenic mice. Proc Natl Acad Sci U S A. 2007; 104:8143-8. [PubMed: 17483470]

Welch, AJ.; van Gemert, MJC. Optical-Thermal Response of Laser-Irradiated Tissue. 2. Plenum Press; New York: 2012.

Wells J, Kao C, Jansen ED, Konrad P, Mahadevan-Jansen A. Application of infrared light for in vivo neural stimulation. J Biomed Opt. 2005a; 10:064003. [PubMed: 16409069]

Wells J, Konrad P, Kao C, Jansen ED, Mahadevan-Jansen A. Pulsed laser versus electrical energy for peripheral nerve stimulation. Journal of neuroscience methods. 2007a; 163:326-37. [PubMed: 17537515]

Wells J, Kao C, Mariappan K, Albea J, Jansen ED, Konrad P, Mahadevan-Jansen A. Optical stimulation of neural tissue in vivo. Optics Lett. 2005b; 30:504-506.

Wells J, Kao C, Konrad P, Milner T, Kim J, Mahadevan-Jansen A, Jansen ED. Biophysical mechanisms of transient optical stimulation of peripheral nerve. Biophysical Journal. 2007b; 93:2567-80. [PubMed: 17526565]

Wells JD, Thomsen S, Whitaker P, Jansen ED, Kao CC, Konrad PE, Mahadevan-Jansen A. Optically mediated nerve stimulation: Identification of injury thresholds. Lasers in surgery and medicine. 2007c; 39:513-26. [PubMed: 17659590]

Wen L, Wang H, Tanimoto S, Egawa R, Matsuzaka Y, Mushiake H, Ishizuka T, Yawo H. Optocurrent-clamp actuation of cortical neurons using a strategically designed channelrhodopsin. PLoS One. 2010; 5:e12893. [PubMed: 20886118]

Wenzel GI, Balster S, Zhang K, Lim HH, Reich U, Massow O, Lubatschowski H, Ertmer W, Lenarz T, Reuter G. Green laser light activates the inner ear. Journal of biomedical optics. 2009; 14:044007. [PubMed: 19725719]

Wesselmann U, Lin SF, Rymer WZ. Effects of Q-switched Nd:YAG laser irradiation on neural impulse propagation: I. Spinal cord. Physiological chemistry and physics and medical. NMR. 1991a; 23:67-80.

Wesselmann U, Lin SF, Rymer WZ. Effects of Q-switched Nd:YAG laser irradiation on neural impulse propagation: II. Dorsal roots and peripheral nerves. Physiological chemistry and physics and medical. NMR. 1991b; 23:81-100.

Wesselmann U, Kerns JM, Rymer WZ. Laser effects on myelinated and nonmyelinated fibers in the rat peroneal nerve: a quantitative ultrastructural analysis. Experimental neurology. 1994; 129:25765. [PubMed: 7525332]

Wilcox M, Viola RW, Johnson KW, Billington AP, Carpenter BK, McCray JA, Guzikowski AP, Hess GP. Synthesis of photolabile "precursors" of amino acid neurotransmitters. J Org Chem. 1990; 55:1585-1589.

Wininger FA, Schei JL, Rector DM. Complete optical neurophysiology: toward optical stimulation and recording of neural tissue. Appl Opt. 2009; 48:218-224.

Xia N, Wu XY, Wang X, Mou ZX, Wang MQ, Gu X, Zheng XL, Hou WS. Pulsed 808-nm infrared laser stimulation of the auditory nerve in guinea pig cochlea. Lasers in medical science. 2013

Yao J, Liu B, Qin F. Rapid temperature jump by infrared diode laser irradiation for patch-clamp studies. Biophysical Journal. 2009; 96:3611-9. [PubMed: 19413966]

Yizhar O, Fenno LE, Davidson TJ, Mogri M, Deisseroth K. Optogenetics in neural systems. Neuron. 2011a; 71:9-34. [PubMed: 21745635]

Yizhar O, Fenno LE, Prigge M, Schneider F, Davidson TJ, O’Shea DJ, Sohal VS, Goshen I, Finkelstein J, Paz JT, Stehfest K, Fudim R, Ramakrishnan C, Huguenard JR, Hegemann P, Deisseroth K. Neocortical excitation/inhibition balance in information processing and social dysfunction. Nature. 2011b; 477:171-8. [PubMed: 21796121]

Young H, Tan X, Richter C-P. Target structures in the cochlea for infrared neural stimulation (INS). Proc of SPIE 8928-104. 2014:1-7.

Zeng H, Madisen L. Mouse transgenic approaches in optogenetics. Prog Brain Res. 2012; 196:193213. [PubMed: 22341327]

Zhang F, Wang LP, Boyden ES, Deisseroth K. Channelrhodopsin-2 and optical control of excitable cells. Nature methods. 2006; 3:785-92. [PubMed: 16990810] 
Zhang F, Aravanis AM, Adamantidis A, de Lecea L, Deisseroth K. Circuit-breakers: optical technologies for probing neural signals and systems. Nature reviews Neuroscience. 2007a; 8:577-81.

Zhang F, Gradinaru V, Adamantidis AR, Durand R, Airan RD, de Lecea L, Deisseroth K. Optogenetic interrogation of neural circuits: technology for probing mammalian brain structures. Nat Protoc. 2010; 5:439-56. [PubMed: 20203662]

Zhang F, Prigge M, Beyriere F, Tsunoda SP, Mattis J, Yizhar O, Hegemann P, Deisseroth K. Redshifted optogenetic excitation: a tool for fast neural control derived from Volvox carteri. Nat Neurosci. 2008; 11:631-3. [PubMed: 18432196]

Zhang F, Vierock J, Yizhar O, Fenno LE, Tsunoda S, Kianianmomeni A, Prigge M, Berndt A, Cushman J, Polle J, Magnuson J, Hegemann P, Deisseroth K. The microbial opsin family of optogenetic tools. Cell. 2011; 147:1446-57. [PubMed: 22196724]

Zhang KY, Wenzel GI, Balster S, Lim HH, Lubatschowski H, Lenarz T, Ertmer W, Reuter G. Optoacoustic induced vibrations within the inner ear. Opt Express. 2009; 17:23037-43. [PubMed: 20052230]

Zhang W, Ge W, Wang Z. A toolbox for light control of Drosophila behaviors through Channelrhodopsin 2-mediated photoactivation of targeted neurons. Eur J Neurosci. 2007b; 26:2405-16. [PubMed: 17970730]

Zheng J, Dai C, Steyger PS, Kim Y, Vass Z, Ren T, Nuttall AL. Vanilloid receptors in hearing: altered cochlear sensitivity by vanilloids and expression of TRPV1 in the organ of corti. J Neurophysiol. 2003; 90:444-55. [PubMed: 12660354]

Zhu P, Narita Y, Bundschuh ST, Fajardo O, Scharer YP, Chattopadhyaya B, Bouldoires EA, Stepien AE, Deisseroth K, Arber S, Sprengel R, Rijli FM, Friedrich RW. Optogenetic Dissection of Neuronal Circuits in Zebrafish using Viral Gene Transfer and the Tet System. Front Neural Circuits. 2009; 3:21. [PubMed: 20126518] 


\section{Research Highlights}

- The impact of using photons to stimulate neurons for scientific questions

- Infrared neural stimulation of neurons target spiral ganglion cell bodies

- Optogenetics and its importance for the cochlea

- Thermogenetics and its importance for the cochlea 


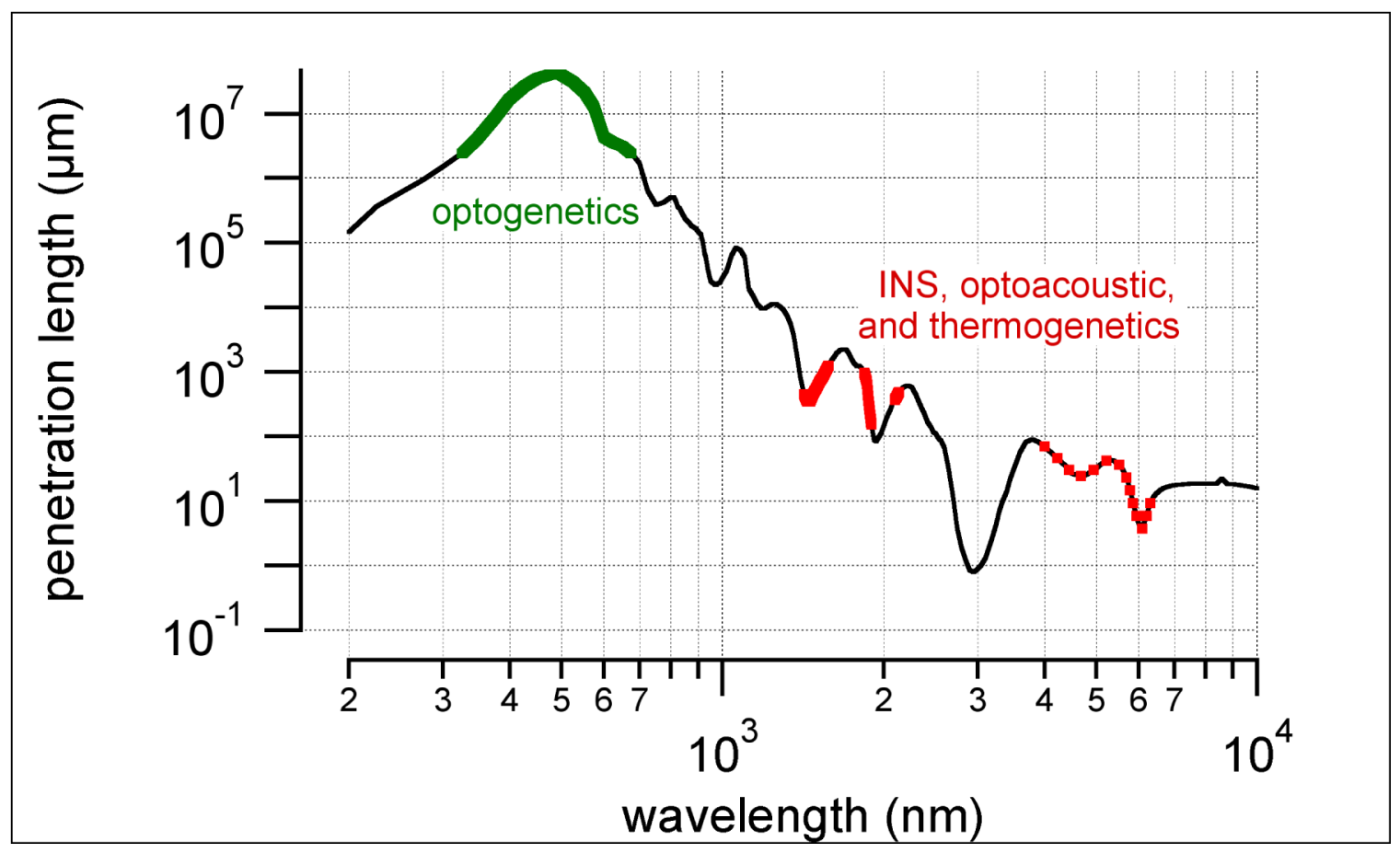

Figure 1.

The plot shows the penetration depth for radiation of different wavelength into water. The data were obtained from Hale 1973. Colored sections reflect the wavelength used for the different optical methods described. Green represents the range of radiation wavelengths used for optogenetics, red for thermogenetics, optoacoustics and INS. For the red dotted line it has been shown in the rat sciatic nerve that stimulation can be achieved. However, at present, it is not possible to deliver the radiation with optical fibers. 

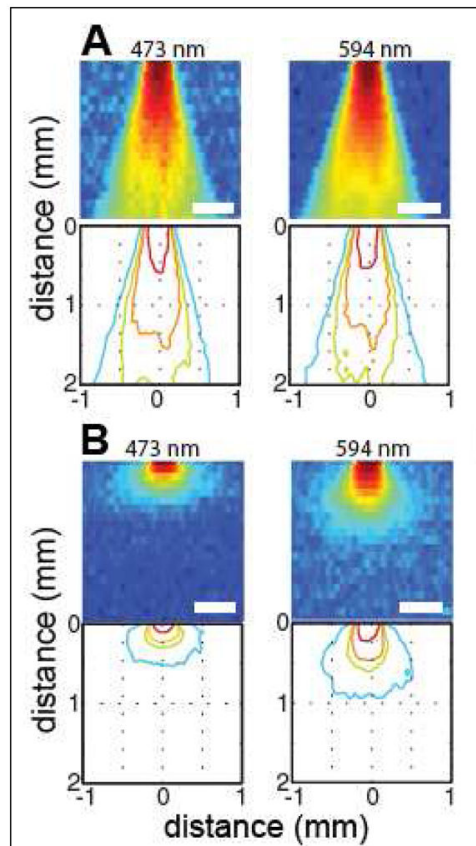

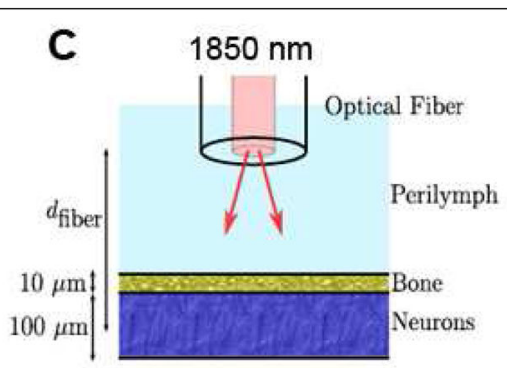

$D_{1850}$

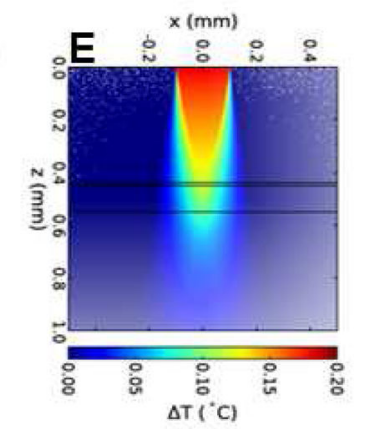

Figure 2.

Images are sections through a 3D map of light intensity along the axis of an illuminating fiber. Contour maps of the image data show iso-intensity lines at $50 \%, 10 \%, 5 \%$, and $1 \%$ of maximum. $\underline{\mathbf{A}}$ shows the plots for saline solution and $\underline{\mathbf{B}}$ for rat gray matter obtained for two different radiation wavelengths, $473 \mathrm{~nm}$ or yellow and $594 \mathrm{~nm}$ or blue. Scatter in brain tissue reduces the penetration depth significantly when compared with saline solution. Also, blue light has a longer penetration depth. $\underline{\mathbf{C}-\mathbf{D}}$ are reproduced from Thompson et al., 2012. $\underline{\mathbf{C}-\mathbf{D}}$ shows an example of a Monte Carlo simulation. In the model an optical fiber is positioned $500 \mu \mathrm{m}$ from the center of a nerve layer $\underline{\mathbf{C}}$. For the modeling the following parameters are assumed: $\lambda=1850 \mathrm{~nm}, 200 \mu \mathrm{m}$ optical fiber, $\mathrm{NA}=0.22, \mathrm{n}_{\text {photons }}=10^{11}$, radiant energy $=25 \mu \mathrm{J} /$ pulse). $\underline{\mathbf{E}}$ shows the result form the modulation and indicate little effect by the tissue on the photon distribution. $\underline{\mathbf{D}}$ is the same as $\underline{\mathbf{E}}$ but scaled to the plots $\underline{\mathbf{A}}$ and $\underline{\mathbf{B} . \mathbf{A}}$ and $\underline{\mathbf{B}}$ are plots reproduced from Yizhar et al. 2011. 


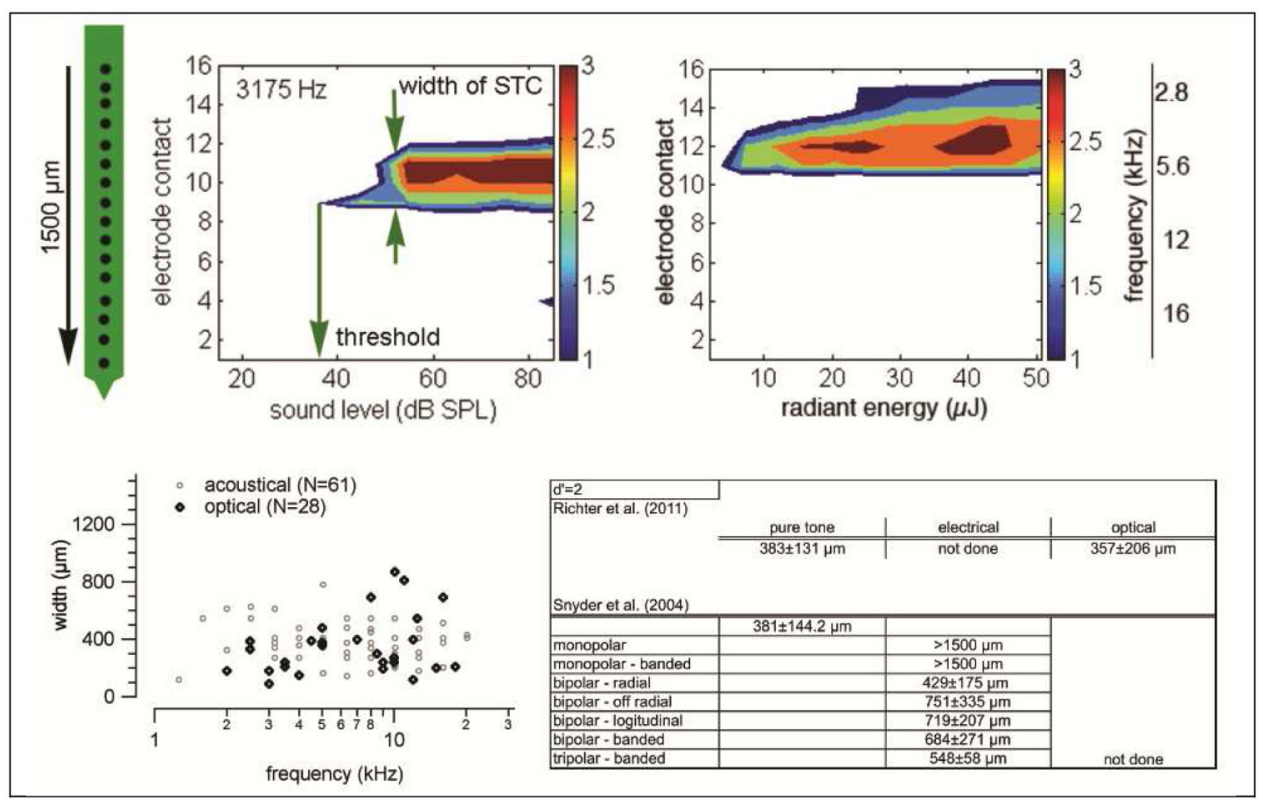

Figure 3.

The top, left panel shows an acoustic spatial tuning curve (STC) recorded on the 16channel, penetrating electrode array inserted into the inferior colliculus. The curve gives a relative measure of the area of the cochlea activated by the acoustic tones. The inferior colliculus retains the tonotopic map of the cochlea, with high frequencies encoded at the deep layers of the IC (electrode 1) and low frequencies encoded more superficially (electrode 16). The top, right panel shows an optical spatial tuning curve for cochlear INS. The bottom, left panel shows the widths of many acoustic and optical STCs. The widths of optical STCs overlap entirely with the acoustic STCs. A smaller width indicates a more spatially selective stimulus. The bottom, right panel gives a comparison of widths (mean \pm s.d.) measured in our study and STC widths measured by Snyder et al. (2004) for various electrical stimulation configurations. Note that the reference values of acoustic STC widths are identical between the two studies. Panels of the figure 3 are modified figures from Richter et al. (2011). 


\begin{tabular}{|c|c|c|c|c|c|c|c|c|c|c|c|c|c|}
\hline 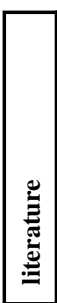 & 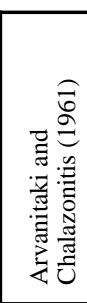 & 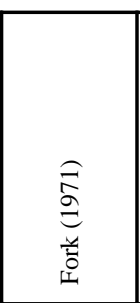 & 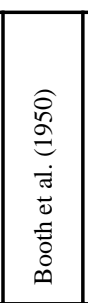 & 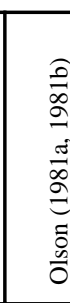 & & 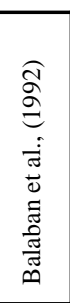 & 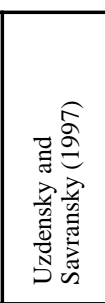 & 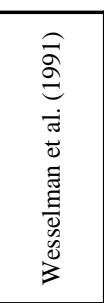 & 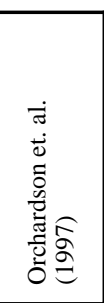 & 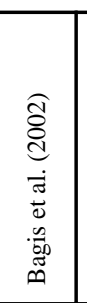 & 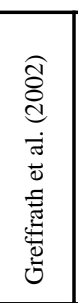 & 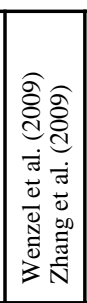 & 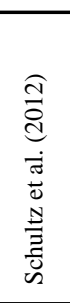 \\
\hline 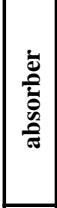 & 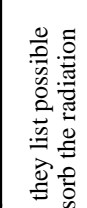 & 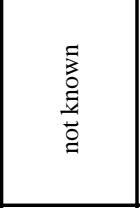 & 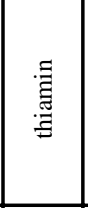 & 尊 & & 莺 & 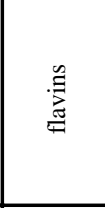 & & & & & & 苞 \\
\hline छ & 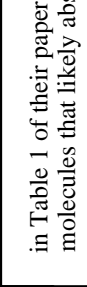 & 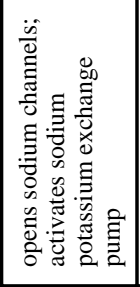 & 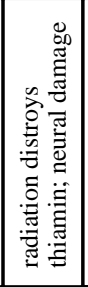 & 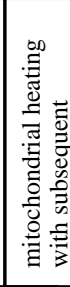 & & 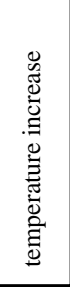 & 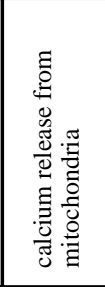 & 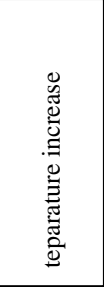 & 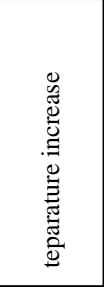 & & 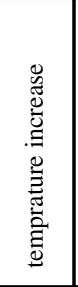 & 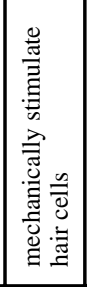 & 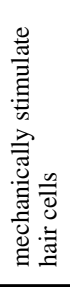 \\
\hline 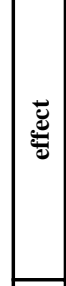 & 苛 & 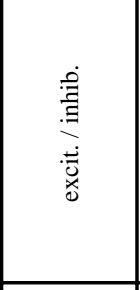 & 音 & 音 & 㥼 & 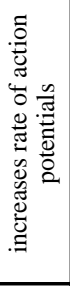 & 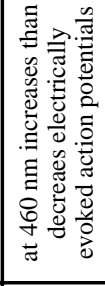 & 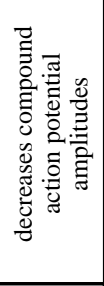 & 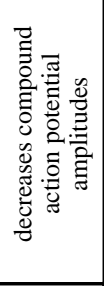 & 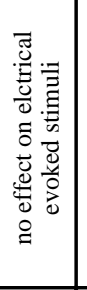 & 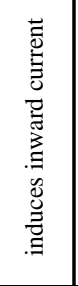 & 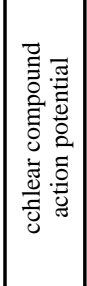 & 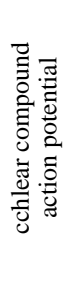 \\
\hline 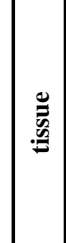 & 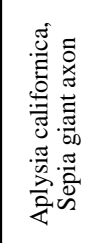 & 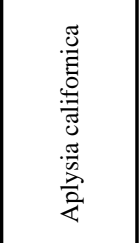 & & 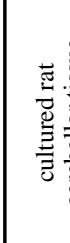 & & 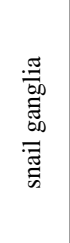 & 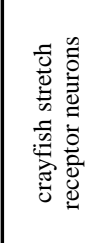 & 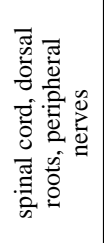 & 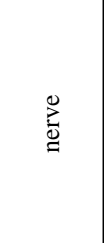 & 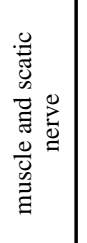 & 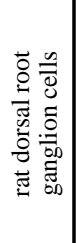 & 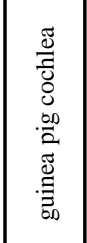 & 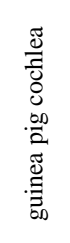 \\
\hline : & 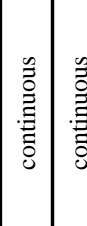 & 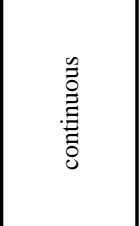 & 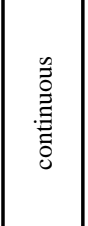 & 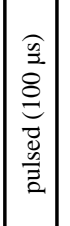 & 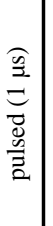 & 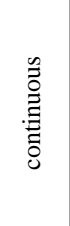 & 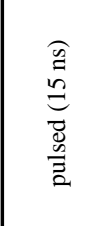 & 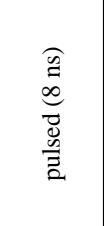 & 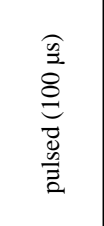 & 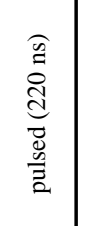 & 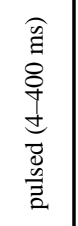 & 氮 & 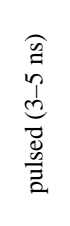 \\
\hline 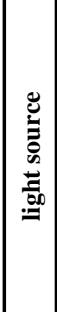 & 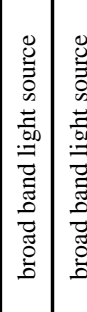 & 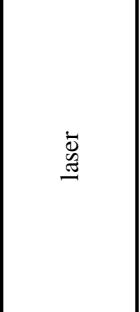 & 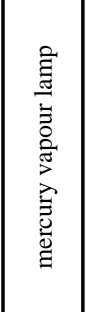 & 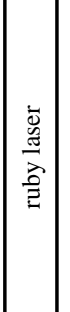 & 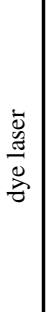 & 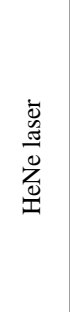 & 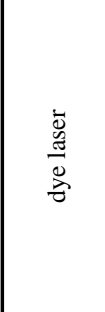 & 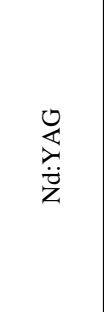 & $\begin{array}{l}\text { 这 } \\
\dot{\ddot{z}}\end{array}$ & 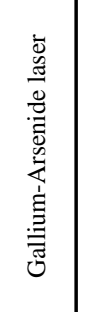 & 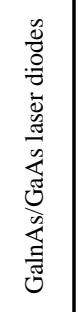 & 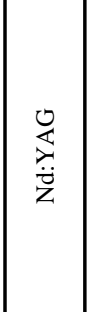 & 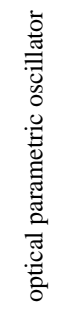 \\
\hline 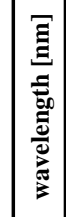 & 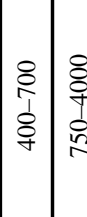 & 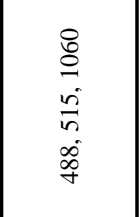 & 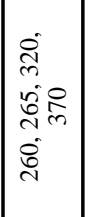 & 菏 & 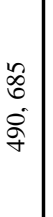 & $\tilde{\tilde{b}}$ & 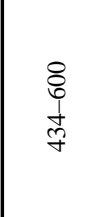 & 壱 & 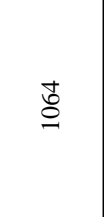 & 壳 & $\stackrel{\infty}{\infty}$ & $\tilde{n}$ & $\begin{array}{l}\frac{n}{\pi} \\
\frac{1}{q}\end{array}$ \\
\hline
\end{tabular}




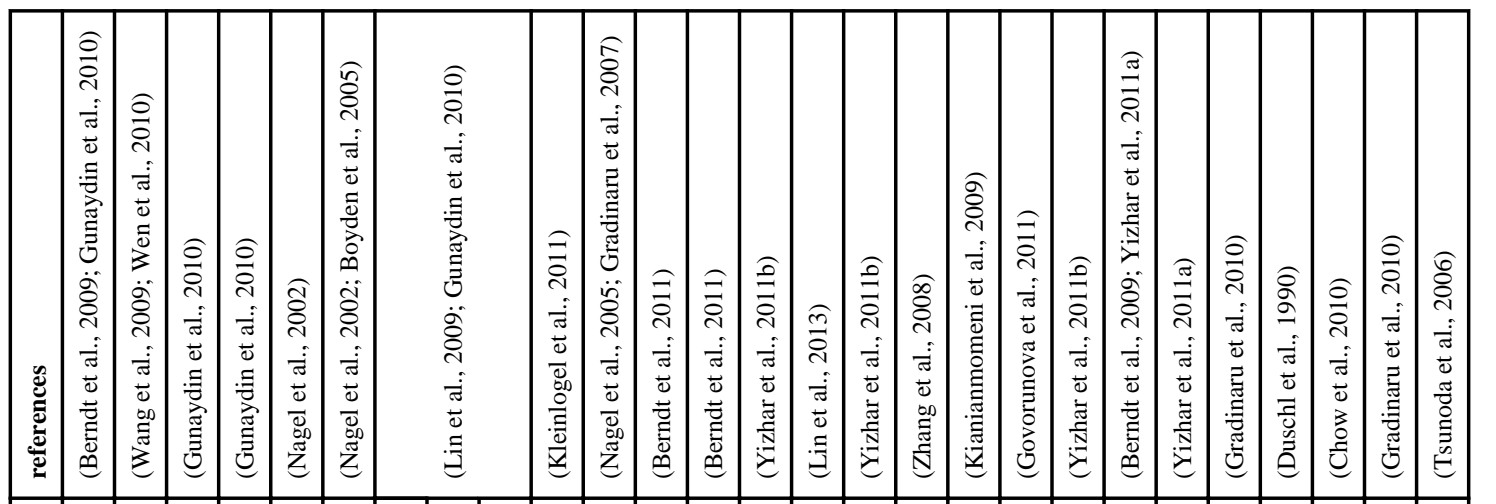

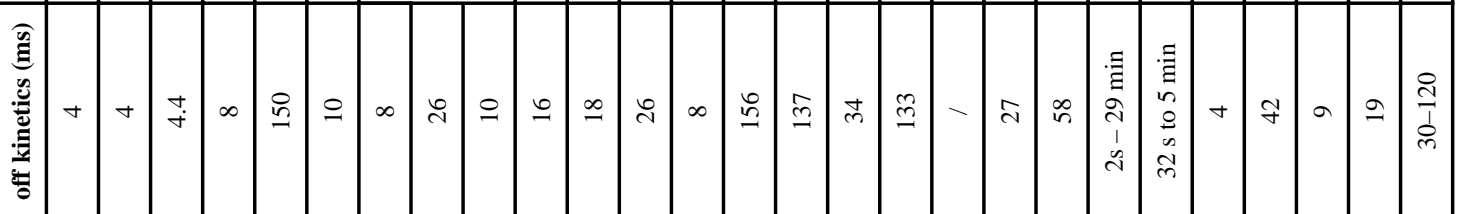

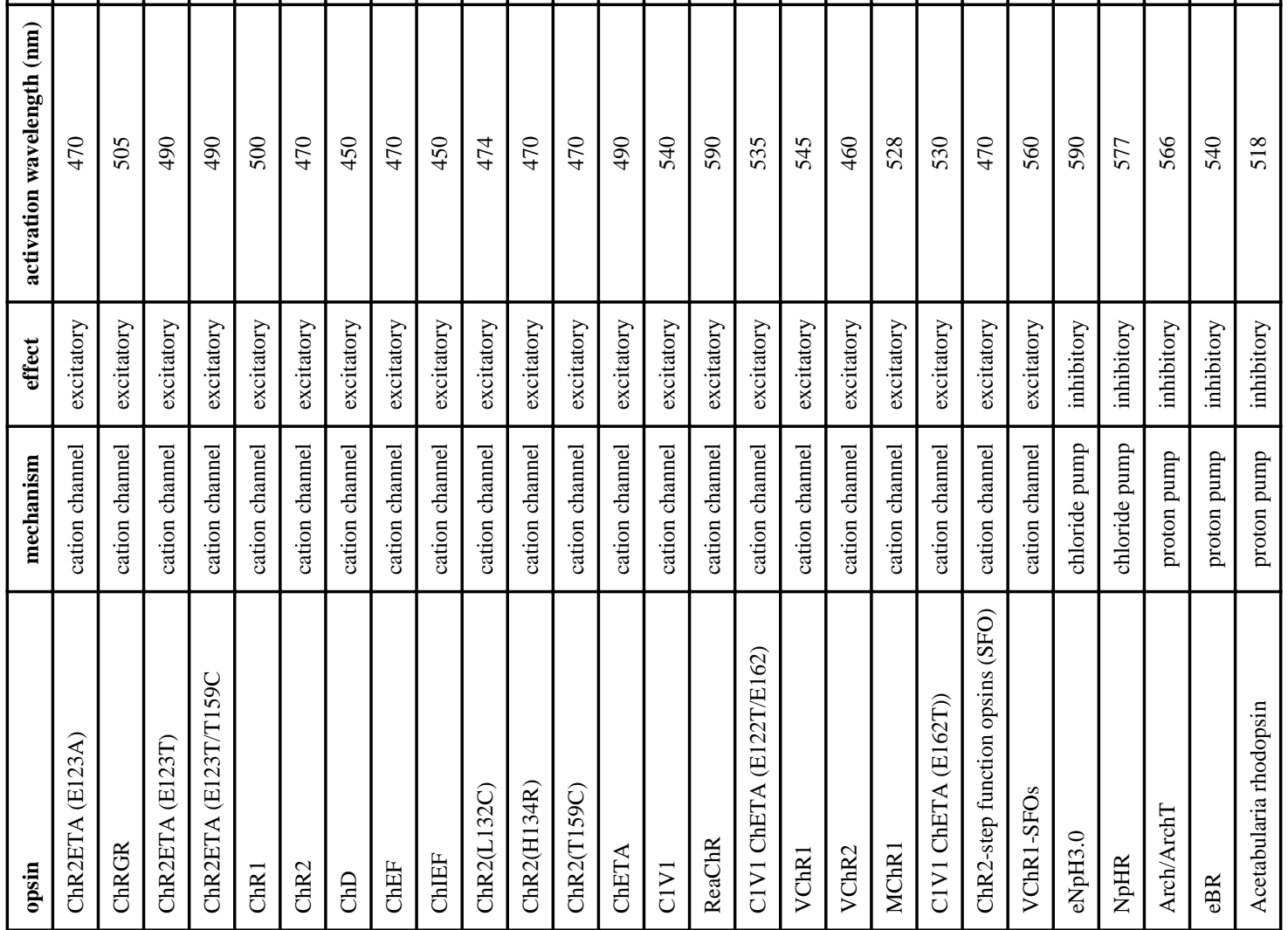


Table 3

Comparison between INS, optogenetics, and optoacoustics

\begin{tabular}{|c|c|c|c|}
\hline \multicolumn{4}{|c|}{ Features } \\
\hline & Optogenetics & INS & Photoacoustics \\
\hline & & thermal confinement & stress confinement \\
\hline Mechanism & $\begin{array}{l}\text { Expression of light sensitive } \\
\text { ion channels in the plasma } \\
\text { membrane. The ion channel/ } \\
\text { transporter expressed } \\
\text { determines the sensitivity to } \\
\text { the radiation wavelength and } \\
\text { whether inhibition or } \\
\text { excitation occurs. }\end{array}$ & $\begin{array}{l}\text { Confined heating of the plasma membrane. } \\
\text { Heating is slow enough (>1 } \mathrm{ss}) \text { that stress } \\
\text { waves can travel from the heated volume but } \\
\text { the heat delivered still remains confined in } \\
\text { the target volume. Radiant energy and pulse } \\
\text { length determine whether stimulation results } \\
\text { in excitation or inhibition. }\end{array}$ & $\begin{array}{l}\text { Radiant energy is delivered } \\
\text { faster than a stress relaxation } \\
\text { wave can travel out of the } \\
\text { heated volume }(\ll 1 \mu \mathrm{s}) \text {, which } \\
\text { can results in the generation of } \\
\text { considerable stress waves and } \\
\text { pressure build-up }\end{array}$ \\
\hline Wavelength & $\begin{array}{l}441,450,470,485,500,535 \\
540,545,560,566,590 \mathrm{~nm}\end{array}$ & $\begin{array}{l}\text { Typically, but not limited to } 1400-1600 \mathrm{~nm} \\
\text { and } 1840-2100 \mathrm{~nm}\end{array}$ & $\begin{array}{l}\text { Typically, but not limited to } \\
532 \mathrm{~nm} \text { and } 420-2150 \mathrm{~nm}\end{array}$ \\
\hline Laser parameter & $\begin{array}{l}\text { Pulse length } 1-10 \mathrm{~ms} \text {, } \\
\text { irradiance } 1-10 \mathrm{~W} / \mathrm{cm}^{2}\end{array}$ & $\begin{array}{l}\text { Pulse length } 5 \mu \text { s to several ms, pulse } \\
\text { repetition rate up to } 1 \mathrm{kHz} \text { tested, threshold } \\
\text { radiant exposure } \sim 15 \mu \mathrm{J} / \mathrm{cm}^{2} \text { to } 1500 \mu \mathrm{J} / \mathrm{cm}^{2}\end{array}$ & $\begin{array}{l}\text { Pulse length is typically } 3-10 \\
\text { ns, radiant energy } 0-6 \mu \mathrm{J} / \mathrm{pulse} \text {; } \\
\text { pulse repetition rate }<10 \mathrm{~Hz} \text {. }\end{array}$ \\
\hline Power for stimulation & $1-10 \mathrm{~W} / \mathrm{cm}^{2}$ & As low as $40 \mathrm{~mW}$; & \\
\hline Temporal properties & $\begin{array}{l}\text { Typically less than } 50 \mathrm{~Hz} \text {, } \\
\text { novel ChR2 mutants respond } \\
\text { up to } 200 \mathrm{~Hz} \text {. }\end{array}$ & $\begin{array}{l}\text { Sustained CAP responses shown up to } 1 \\
\mathrm{kHz} \text {; single fiber responses } \sim 100-150 \mathrm{~Hz} \text {. } \\
\text { Onset response times } \sim 2.5 \mathrm{~ms}\end{array}$ & \\
\hline \multicolumn{4}{|c|}{ Challenges } \\
\hline "chromophore" & $\begin{array}{l}\text { Needs the targeted and } \\
\text { selective expression of ion } \\
\text { channels in a selected type of } \\
\text { neurons }\end{array}$ & $\begin{array}{l}\text { Water is the main absorber and readily } \\
\text { available at the cell; water between source } \\
\text { results in unnecessary heating }\end{array}$ & \\
\hline $\mathrm{pH}$ changes & $\begin{array}{l}\text { Sustained stimulation changes } \\
\text { cell } \mathrm{pH} \text { with risk of damage }\end{array}$ & Not documented & \\
\hline Heating of tissue & Not documented & $\begin{array}{l}\text { Limits rate and maximum radiant exposure } \\
\text { of stimulation }\end{array}$ & $\begin{array}{l}\text { Is likely and will limit rate and } \\
\text { maximum radiant exposure of } \\
\text { the stimulation }\end{array}$ \\
\hline pressure wave formation & not documented & $\begin{array}{l}\text { stress relaxation waves are generated an can } \\
\text { result in photoacoustic stimulation }\end{array}$ & used for stimulation \\
\hline
\end{tabular}

